Article

\title{
Exploring Complementary Models Consisting of Machine Learning Algorithms for Landslide Susceptibility Mapping
}

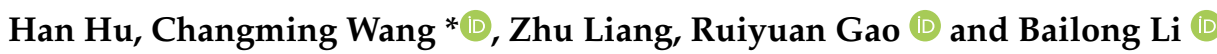 \\ College of Construction Engineering, Jilin University, Changchun 130012, China; \\ huhan18@mails.jlu.edu.cn (H.H.); liangzhu19@mails.jlu.edu.cn (Z.L.); gaory18@mails.jlu.edu.cn (R.G.); \\ lb119@mails.jlu.edu.cn (B.L.) \\ * Correspondence: wangcm@jlu.edu.cn; Tel.: +86-135-0441-8751
}

Citation: $\mathrm{Hu}, \mathrm{H} . ;$ Wang, C.; Liang, Z.; Gao, R.; Li, B. Exploring

Complementary Models Consisting of Machine Learning Algorithms for Landslide Susceptibility Mapping. ISPRS Int. J. Geo-Inf. 2021, 10, 639. https://doi.org/10.3390/ijgi10100639

Academic Editor: Wolfgang Kainz

Received: 3 August 2021

Accepted: 21 September 2021

Published: 24 September 2021

Publisher's Note: MDPI stays neutral with regard to jurisdictional claims in published maps and institutional affiliations.

Copyright: () 2021 by the authors. Licensee MDPI, Basel, Switzerland. This article is an open access article distributed under the terms and conditions of the Creative Commons Attribution (CC BY) license (https:// creativecommons.org/licenses/by/ $4.0 /)$.
Abstract: Landslides frequently occur because of natural or human factors. Landslides cause huge losses to the economy as well as human beings every year around the globe. Landslide susceptibility prediction (LSP) plays a key role in the prevention of landslides and has been under investigation for years. Although new machine learning algorithms have achieved excellent performance in terms of prediction accuracy, a sufficient quantity of training samples is essential. In contrast, it is hard to obtain enough landslide samples in most the areas, especially for the county-level area. The present study aims to explore an optimization model in conjunction with conventional unsupervised and supervised learning methods, which performs well with respect to prediction accuracy and comprehensibility. Logistic regression (LR), fuzzy c-means clustering (FCM) and factor analysis (FA) were combined to establish four models: LR model, FCM coupled with LR model, FA coupled with LR model, and FCM, FA coupled with LR model and applied in a specific area. Firstly, an inventory with 114 landslides and 10 conditioning factors was prepared for modeling. Subsequently, four models were applied to LSP. Finally, the performance was evaluated and compared by k-fold cross-validation based on statistical measures. The results showed that the coupled model by FCM, FA and LR achieved the greatest performance among these models with the AUC (Area under the curve) value of 0.827 , accuracy of $85.25 \%$, sensitivity of $74.96 \%$ and specificity of $86.21 \%$. While the LR model performed the worst with an AUC value of 0.736 , accuracy of $77 \%$, sensitivity of $62.52 \%$ and specificity of $72.55 \%$. It was concluded that both the dimension reduction and sample size should be considered in modeling, and the performance can be enhanced by combining complementary methods. The combination of models should be more flexible and purposeful. This work provides reference for related research and better guidance to engineering activities, decision-making by local administrations and land use planning.

Keywords: complementary model; unsupervised and supervised learning; landslide susceptibility prediction; GIS

\section{Introduction}

Landslide is a common and unavoidable form of disaster, especially in mountainous areas where rainfall, earthquakes or, engineering activities frequently occurs. The damages caused by landslides to both humans and the economy are enormous [1,2]. The frequency and scale of landslide outbreaks in China are larger than that of other countries in the world [3]. Therefore, landslides have attracted increasing attention and a significant amount of research has been done, especially in landslide susceptibility prediction (LSP).

In some cases, damages could be avoided or decreased with limits by recognizing the likely locations of future disasters [4]. In the view of seriousness and frequency of landslide, the establishment of prediction models are indispensable and various methods have also proved their effectiveness. Physical-based approaches and heuristic methods are applicable to limited samples and are time-consuming [5,6]. Traditional machine learning methods 
(TMLM) as the Logistic regression (LR) model, clustering analysis and principal component analysis have been well verified in LSP [7-9]. The new machine learning methods (NMLM), such as support vector machines, artificial neural networks and deep learning, have gained consideration with the development of computer technology [10-16]. Ensemble learning offers the possibility to further improve the accuracy and reflection of nonlinear relationships between landslide and conditioning factors [17]. Bagging, boosting and stacking are three commonly applied technologies [18-22]. However, few discussions have focused on the integration of TMLM.

The application of NMLM involves a few hyper-parameters needed to be tuned and optimized with the "black-box" training process, which leads to some limitations in practice [23]. On the other hand, high-quality samples with respect to purity and quantity are essential for the modeling of NMLM, which is hard to obtain, especially for the countylevel area. Therefore, exploring a new ensemble method to ease the above problems is be of great significance. The current study aims to explore a hybrid model consisting of TMLM to improve the accuracy and comprehensibility.

Several researchers have compared the LR model with other models [24]. However, few attempts have combined the LR model with other methods to compensate for its limitations [25]. The LR model, which uses the logistic transformation to calculate probability ratios and to predict the probabilities of events associated with multiple variables, belongs to supervised learning. The coefficients in the regression equation will be affected if there is a multicollinear relationship between the independent variables, and may lead to unsatisfactory prediction results. The data can hardly meet mutual independence between variables in LSP. On the other hand, different catchments highlight different major landsliderelated factors while LR model fails to recognize the difference and lacks pertinence. Hence, the accuracy and reliability of the LR model need to be further improved.

Fuzzy C-means (FCM) clustering belongs to an unsupervised learning model and is used for sorting catchments with similar characteristics into clusters [26]. Factor analysis (FA) belongs to another unsupervised learning model, which is a common tool for solving the problem of "Dimension disaster" and exploring the main conditioning factors of different clusters [27]. Therefore, this study proposes hybrid models combining LR, FCM, and FA. Luoying Town, Pinggu District in Beijing is selected as the study area. Four models, including the LR model, FCM coupled with LR model, FA coupled with LR model, and FCM, FA coupled with LR models, are established to compare and analyze the performance from different angles. The ArcGIS platform is applied to map and extract related data, while Statistical Product and Service Solutions (SPSS) software is used for modeling.

\section{Study Area and Materials}

\subsection{Study Area and Landslide Inventory}

The town of Luoying in the Pinggu District of Beijing, has been suffered from landslides for years (Figure 1). It covers an area of $80.9 \mathrm{~km}^{2}$ with 3200 households and total of 11,000 people. The elevation ranges from about 181 to $1236 \mathrm{~m}$ above from mean sea level. It belongs to the northern temperate continental climate with a large annual temperature difference. The annual precipitation rate in the area is $642 \mathrm{~mm}$, mainly concentrated in late July and early August, accounting for $76 \%$ of the total rainfall. Figure 2 shows the average monthly rainfall (1959-2017) in the area.

The Yanshanian and Indosinian periods were characterized by strong tectonic activity, which forms a series of large folds and faults. Three common lithologies were found during our field investigation: gneiss from Middle Archean $\left(\mathrm{Ar}_{2} \mathrm{wgn}\right)$, quartz sandstone from Mesozoic $\left(\mathrm{Chc}^{3}\right)$ and dolomites from Mesozoic (Cht). Magmatic rocks are not developed in the region, and many kinds of loose solid material accumulations such as landslides and collapse accumulations, were found in the catchments. 


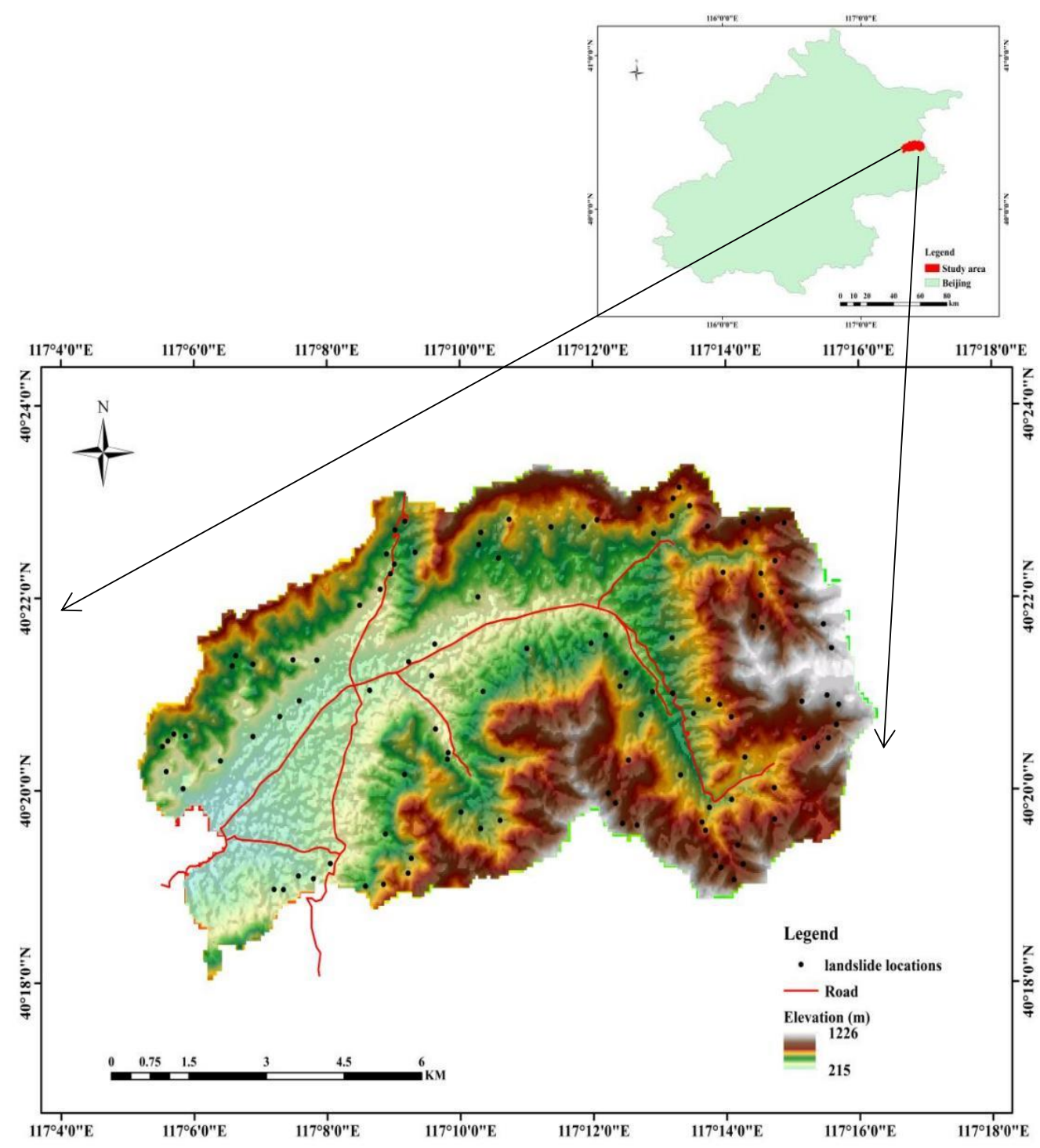

Figure 1. Geographical position of the study area showing landslide locations.

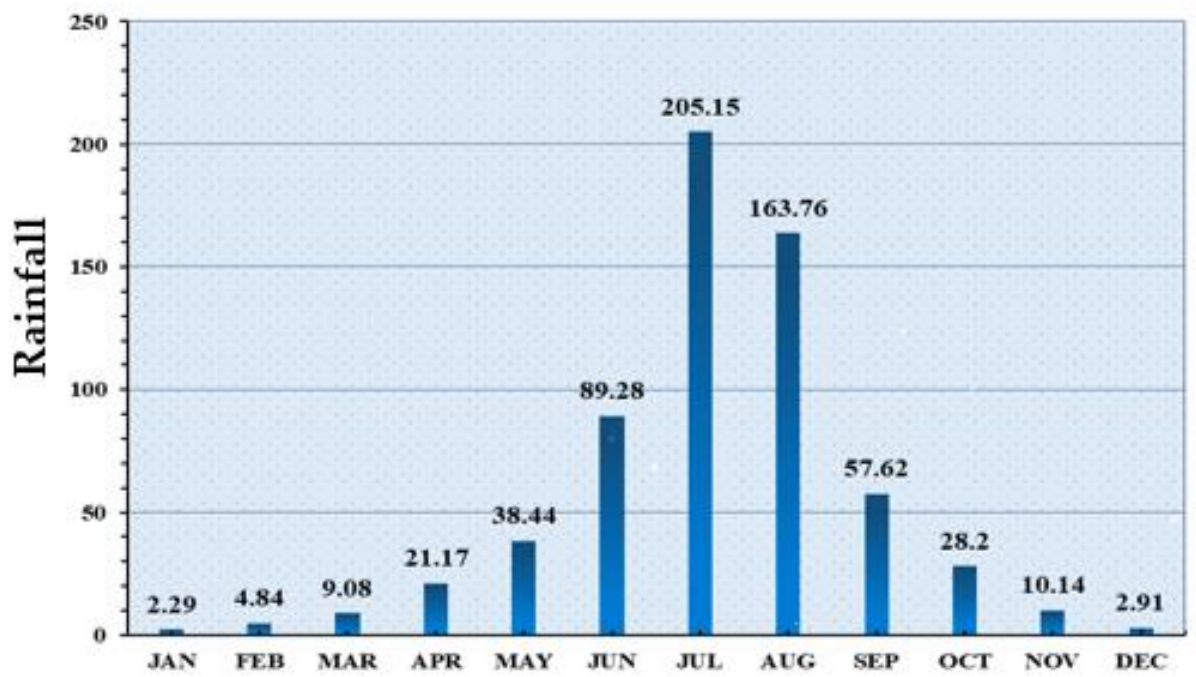

Time/month

Figure 2. Average monthly rainfall data (from 1959 to 2017) for the Pinggu district. 
Tectonic activity in the study area is intense, and natural disasters such as earthquakes, floods and landslides have occurred many times in history (Table 1), which has caused great damage to local villagers. Therefore, LSP was indispensable. According to historical reports (1970 2015), field investigation (2017 2019) (Figure 3), and remote sensing image interpretation, 114 shallow landslides were collected. To reduce the spatial autocorrelation effect between the observation data, improve the rendering effect, and avoid the uncertainty of drawing the landslide boundary, a single point placed at the center of centroid of the region is drawn for each landslide to show the locations (Figure 1). LSP could be considered as a considered as a binary classification problem, which needs both positive and negative samples. The landslide samples were regarded as the positive samples with the "1" label while non-landslide samples as negative samples with " 0 " label. To reduce the bias, the same number of non-landslide samples were selected randomly on the landslide-free area. The maximum area of landslide is $8.9 \times 10^{3} \mathrm{~m}^{2}$, the minimum area is $200 \mathrm{~m}^{2}$, and the average area is $2 \times 10^{3} \mathrm{~m}^{2}$. All shallow landslides triggered by rainfall or earthquakes were considered in the study. For example, on the night of 15 July 1958, the rainfall intensity in the study area reached $144.6 \mathrm{~mm}$, which induced a large number of landslides. Shallow landslides occurred in the area, mainly in July.
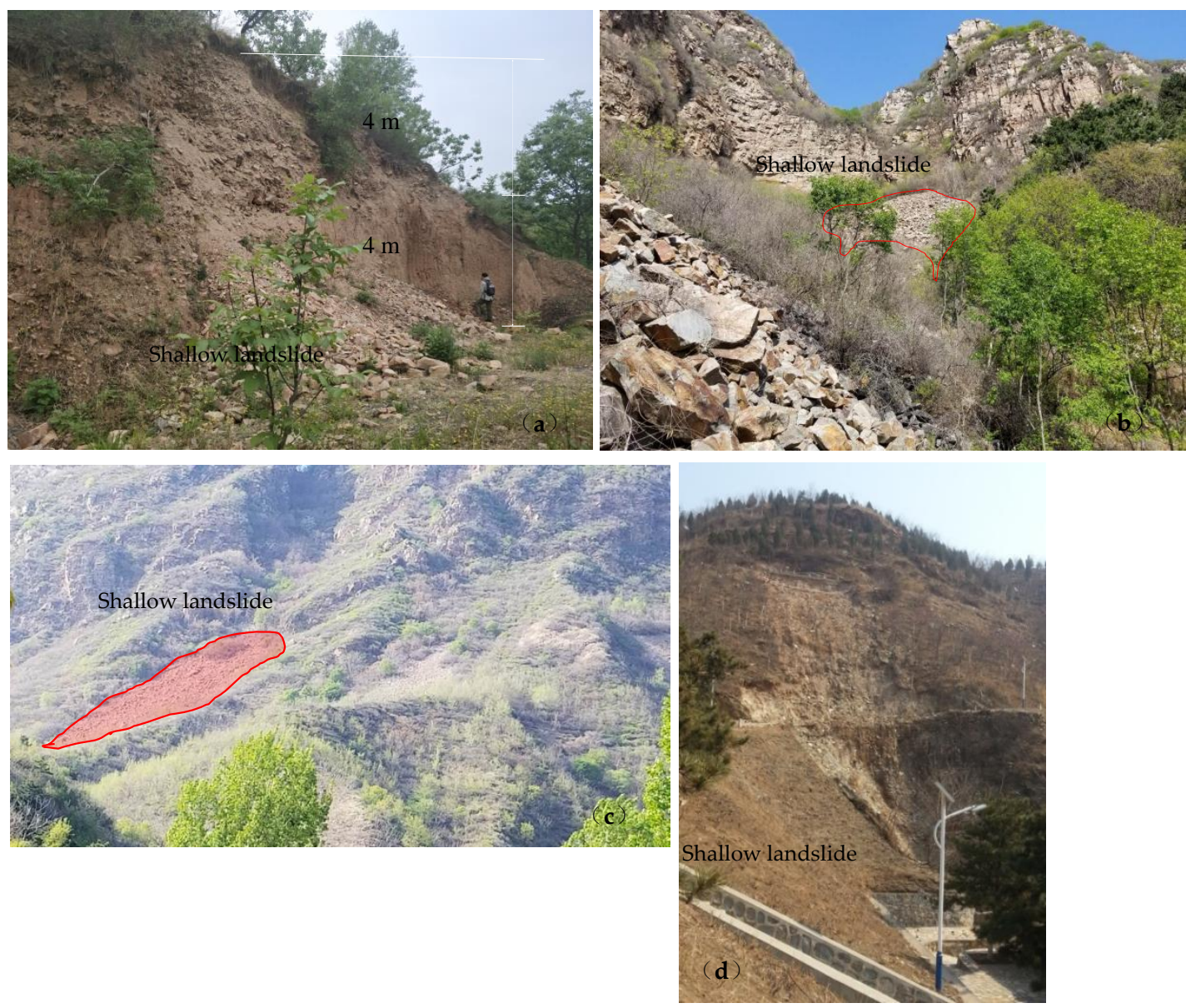

Figure 3. Field investigation photos. (a) Shallow landslide in Hetaowa village; (b) shallow landslide in Guanshang village; (c) shallow landslide in Taoyuan village; (d) shallow landslide in Qingshui village.

Table 1. Statistics of geological disasters in the Pinggu district.

\begin{tabular}{ccccc}
\hline Type & Earthquake & Collapse & Landslide & Statistics Time \\
\hline Quantity & 90 & 168 & 114 & As of October 2016 \\
\hline
\end{tabular}




\subsection{Mapping Unit}

The selection of a mapping unit needs to be considered first, as data extraction is based on spatial primitives. Several methods have been applied to the division of terrain and four kinds of mapping units were obtained: grid unit, slope unit, unique-condition unit and watershed unit [28-31]. The grid unit is the most popular unit applied in LSP due to its simplicity [32]. However, grid units are sensitive to all the uncertainties in the geomorphological mapping. On the other hand, slope units could reflect topographic and geological conditions of a landslide. Landslides occur primarily on slopes, and slope units which are hydrological terrain units bounded by drainage and divide lines are suited for LSP. More information between different units can be found in other works [33]. Therefore, slope units were selected as the mapping unit in this study and the study area is divided into 503 slope units based on the Hydrologic analysis tool in ArcGIS and the results were imported into Google Earth for repeated correction.

\subsection{Conditioning Factors}

Geological disasters are induced by the interaction of internal geological forces and external meteorological hydrology. The conditioning factors usually involve topographical, geological and meteorological conditions, which affect the distribution and frequency of landslides [34]. In this study, ten conditioning factors (F1-F10) were chosen to refer to previous literature [35]. A brief description is stated below:

\subsubsection{Triggering Factors}

Rainfall has been the main triggering factor for landslides for many years. The occurrence of a landslide is affected by both intensity and duration of rainfall. This study selects maximum rainfall of 7 days $(F 1)$ as the predisposing factor, the values of which range from 311.956 to $355.045 \mathrm{~mm}$. The thematic map was generated by kriging interpolation in ArcGIS and 12 precipitation stations nearby the study area were collected as a reference (Figure 4a). Road construction is the key for the development of mountainous areas and unreasonable excavation often leads to landslides. Distance to the road (F2) was obtained using the Euclidean distance interpolation approach, ranging from 36.38 to $2844.85 \mathrm{~m}$ from roads (Figure $4 \mathrm{~b}$ ). Road networks were collected from Landsat $8 \mathrm{LOI}$ images. Earthquake is another important triggering factor in the current study, but the peak ground acceleration is the same. Therefore, rainfall is regarded as the main triggering factor considered in this study and distance to the road as another triggering factor reflecting human activities. 

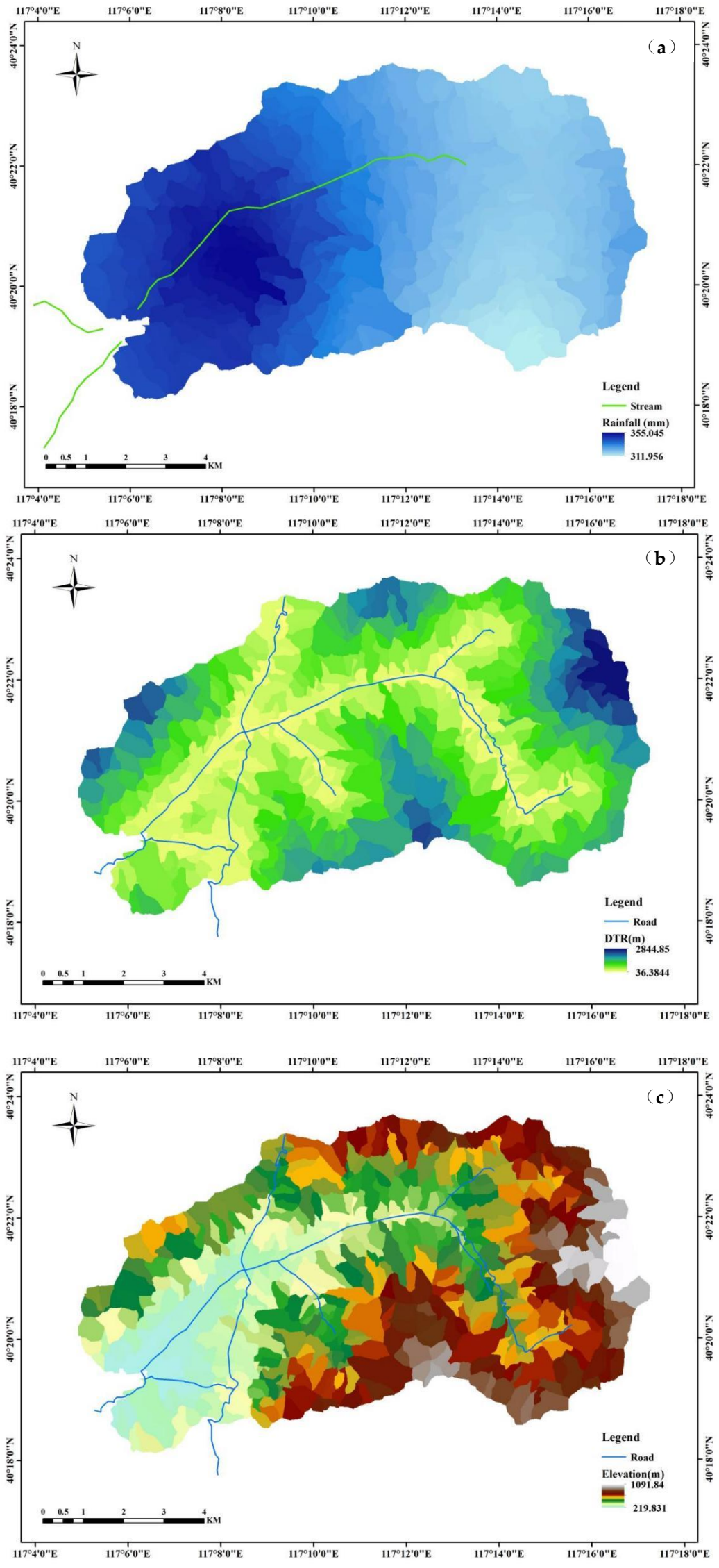

Figure 4. Cont. 

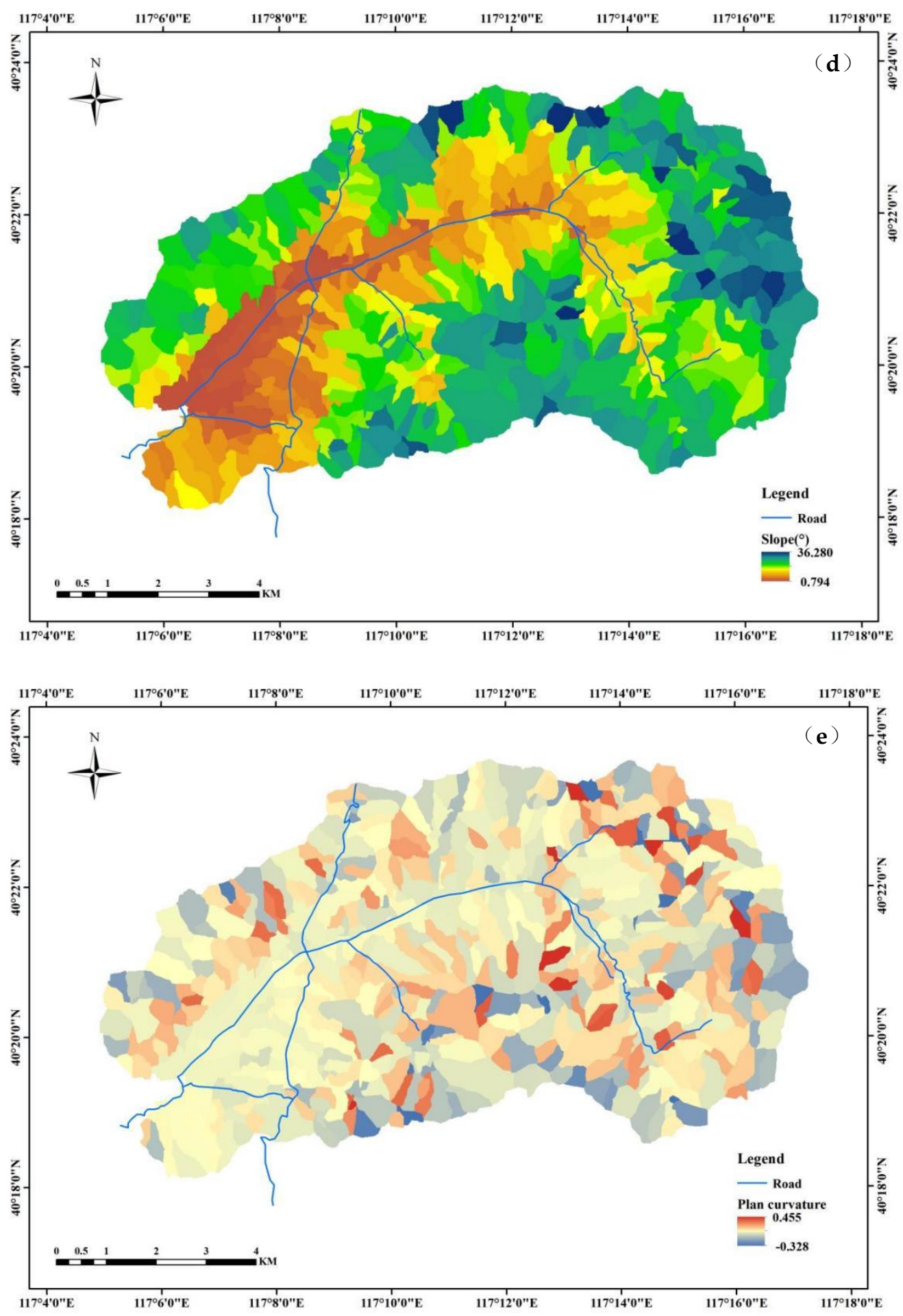

Figure 4. Cont. 

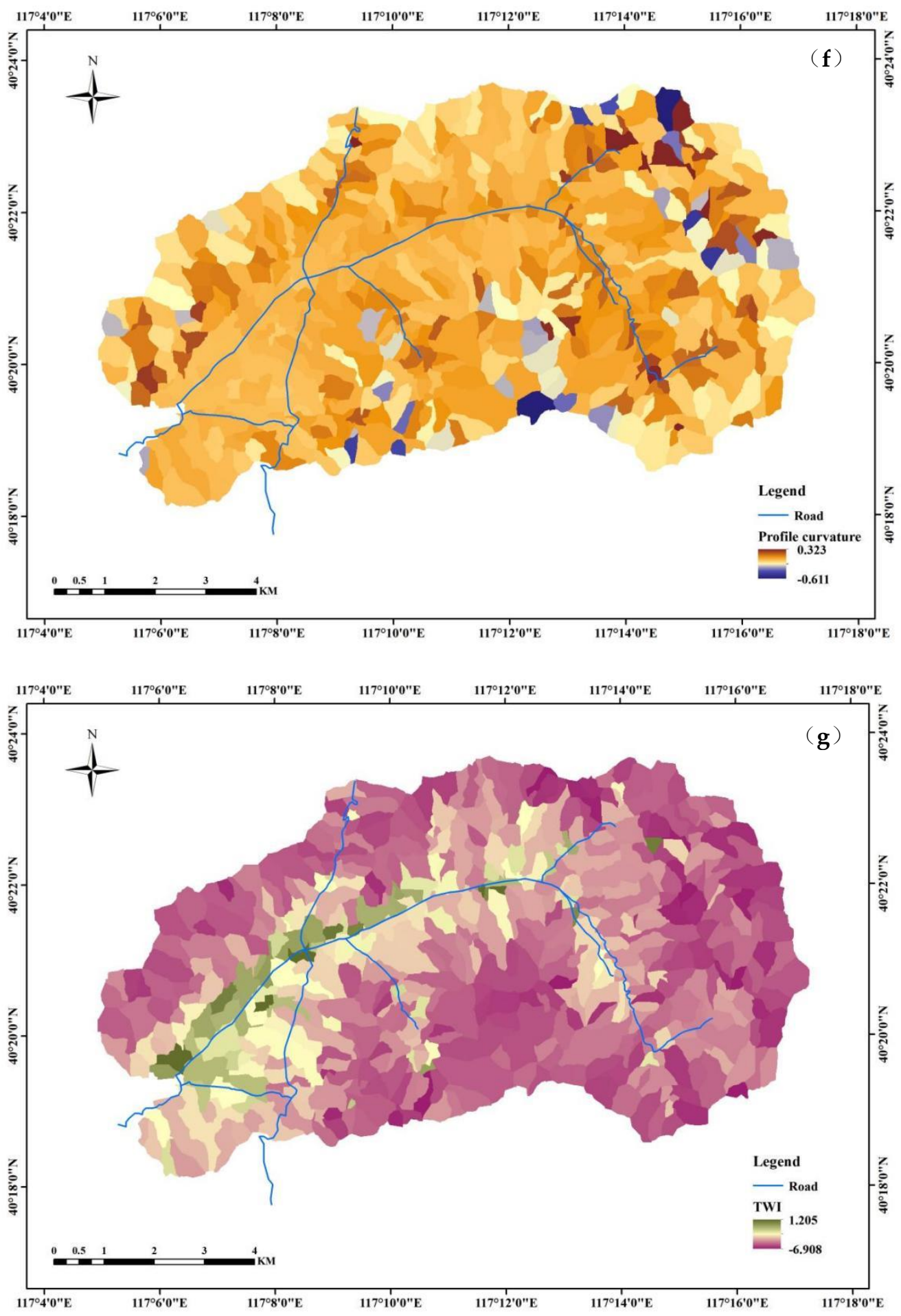

Figure 4. Cont. 

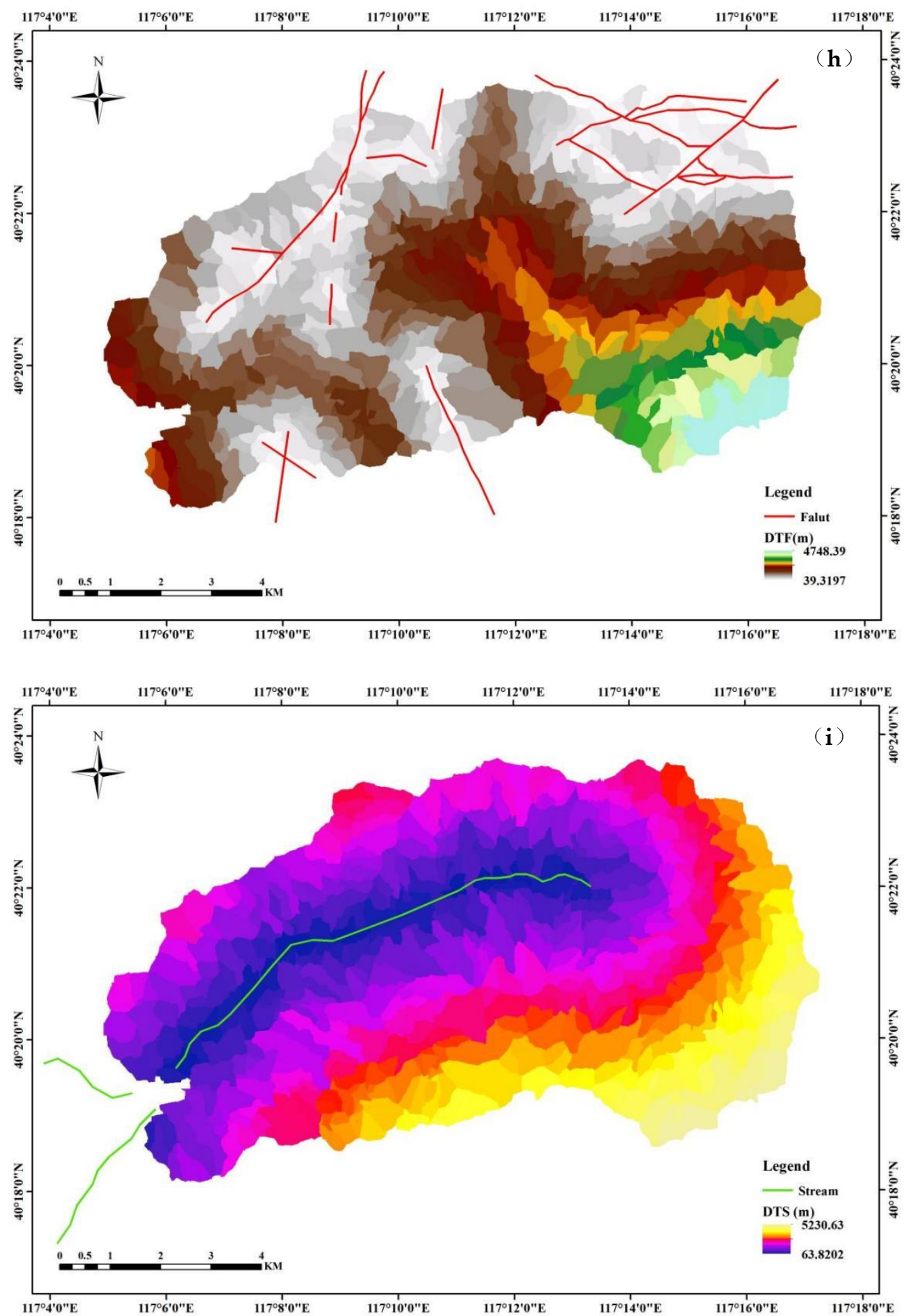

Figure 4. Cont. 


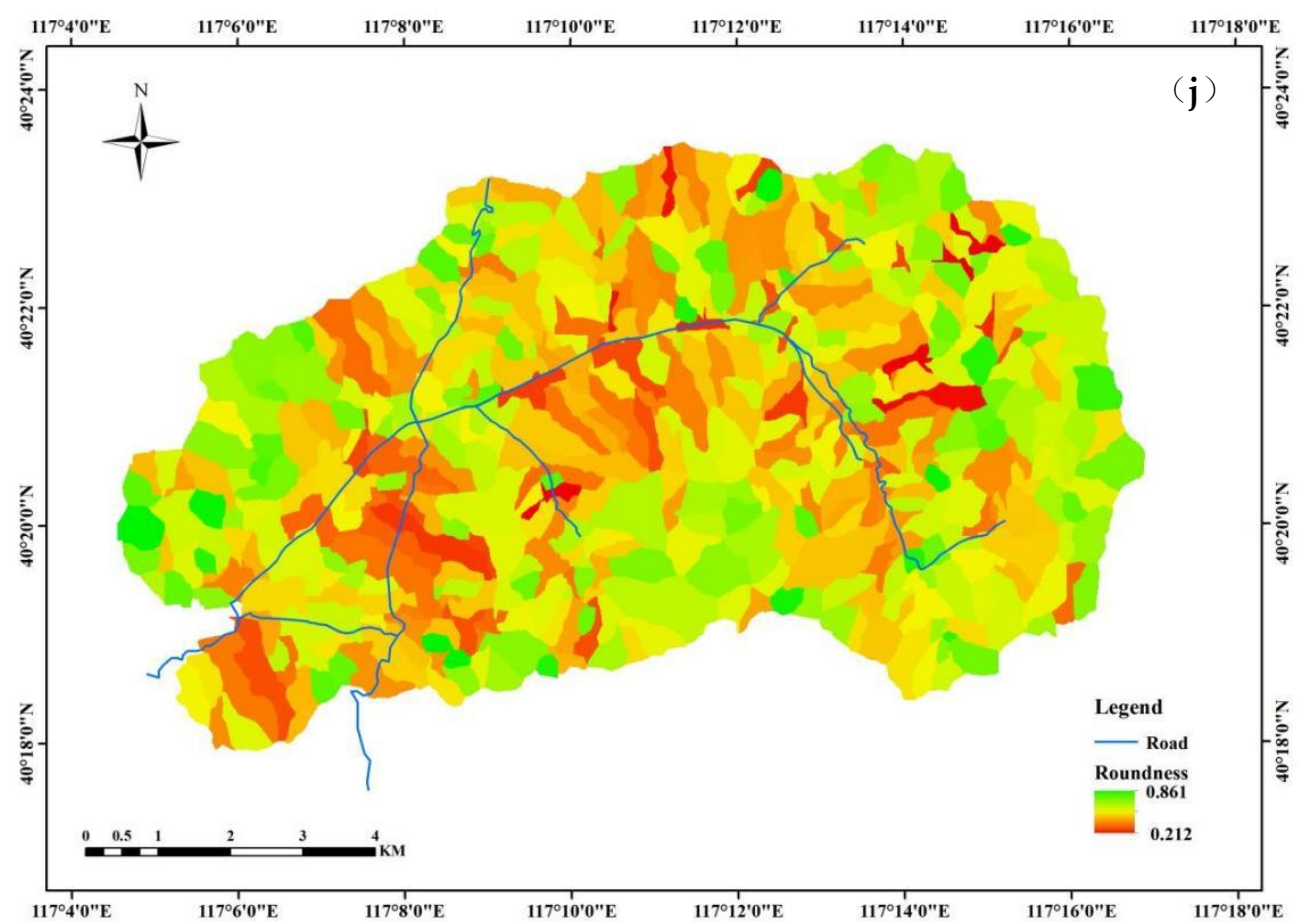

Figure 4. Study area thematic maps: (a) rainfall; (b) distance to road; (c) elevation; (d) slope angle; (e) plan curvature; (f) profile curvature; (g) topographic wetness index; (h) distance to fault; (i) distance to stream; (j) roundness.

\subsubsection{The Topographical Factors}

Topographic related factors as elevation (F3), slope angle (F4), plan curvature (F5), profile curvature $(F 6)$ and topographic wetness index (F7) were originated from the shuttle radar topography mission digital elevation model (SRTM DEM) dataset with a $30 \mathrm{~m} \times 30 \mathrm{~m}$ resolution. The related thematic maps are shown in Figure 4c-g.

\subsubsection{Geological Factors}

Distance to a fault (F8) is closely linked to the occurrence of landslides [36]. Euclidean distance algorithm was applied to calculate the distance from slope units to the faults (in meters), the values of which vary from 39.31 to $4748.39 \mathrm{~m}$ (Figure $4 \mathrm{~h}$ ). The map of faults was obtained from a geological map at a scale of 1:50,000.

Rivers have an effect on its support force to slopes and alternating slopes' pore-water pressure. Therefore, the distance-to-stream (F9) is also considered in the study and the values range from 68.82 to $5230.63 \mathrm{~m}$ from the rivers (Figure 4i) [37].

The plane shape varies from a different stage of development of a landslide. Roundness (F10) is a morphologic factor, which can be calculated with the following equation:

$$
R_{c}=\frac{S}{A}=\frac{4 \pi S}{P}
$$

where $S$ and $P$ represent the area and perimeter of a slope unit, respectively; $A$ is the area of a circle with the same perimeter of a slope unit.

The mean value of each conditioning factor is taken as the attribute of each slope unit, and multiple thematic factor graphs are shown in Figure 4.

\section{Methodology}

\subsection{LR Model}

The LR model commonly applies to describe the relationship between several independent variables, which can be nominal or continuous and a dependent variable which 
can be binary or categorical $[38,39]$. This model is able to calculate the probability of presence or absence based on the predictor variables suitable for LSP. In the present study, the conditioning factors are taken as the independent variables and the occurrence of landslides as the dependent variable. The general form of LR model is as follows [40]:

$$
p=\frac{1}{1-e^{-y}}
$$

where $p$ refers to the probability of a landslide occurrence; $y$ is a linear combination function of the variables as shown in Equation (3):

$$
y=b_{0}+b_{1} x_{1}+b_{2} x_{2}+b_{3} x_{3}+b_{n} x_{n}
$$

where $b_{0}$ is a constant and $b_{1}, b_{2}, \ldots, b_{n}$ are the regression coefficients of the variables $x_{1}$, $x_{2}, \ldots, x_{n}$.

\subsection{FCM Clustering}

The membership of objects belonging to a particular cluster is calculated by FCM and belongs to the soft clustering [41,42]. The core idea is to map data points in a multidimensional space to different cluster sets in the form of membership degrees, thereby determining $C$ cluster centers, minimizing inter-cluster correlation and maximizing intra-cluster correlation. The function and steps of the FCM clustering are defined as shown below:

$$
\begin{gathered}
C_{\mathrm{i}}=\sum_{j=1}^{n} \mu_{i j}^{m} \chi_{j} / \sum_{j-1}^{n} \mu_{i j}^{m} \\
J=\sum_{j=1}^{N} \sum_{i=1}^{C} u_{i j}^{m} d^{2}\left(X_{j}, V_{i}\right) \\
u_{i j}=\frac{1}{\sum_{k=1}^{C}\left(\frac{d_{i j}}{d_{k j}}\right)^{2 /(m-1)}}
\end{gathered}
$$

where $m$ refers to the degree of fuzziness, $u_{i j}$ is the degree of membership of object $x_{i}$ in the cluster $j, d$ represents the Euclidean distance between the $i^{\text {th }}$ clustering center and the $j^{\text {th }}$ sample [43], $J$ is the objective function and $n$ is the number of objects in the database.

Two parameters as $\mathrm{m}$ and the number of cluster centers $C$ need to be determined in advance. This study applies the cluster validity function [44] to determine the number of cluster centers, and $\mathrm{m}$ is assigned as 2 for most applications.

\subsection{FA Model}

The FA model extracts comprehensive factors by exploring the internal dependency of variables. The core idea of FA is to describe the complex relationship between the original variables with the sum of the linear function of the least number of common factors and the special factors. Specifically, the observation data is decomposed into two matrices, one of which is expressed as a common factor. The other matrix is expressed as a special factor. It can be written in matrix form by mathematical expression as shown in Equation (6):

$$
X_{i j}=a_{f 1} f_{1 i}+a_{f 2} f_{2 i}+\ldots+a_{f m} f_{m i}+e_{f i}
$$

where $X$ refers to a measured variable; a represents the factor loading; $f$ is the factor score; $e$ is the special factor; $i$ is the sample number and $m$ is the factor number.

The main steps are as follows:

a. Constructions of comprehensive factors 
The first $m$ rotated factors are extracted as the comprehensive factors the total variance of which is not less than $85 \%$.

b. The factor scores calculation

The Thomson regression method is applied to calculate the factor scores of each factor, which can be represented as:

$$
F=A^{\prime} R^{-1} X
$$

where $A^{\prime} R^{-1}$ refers to the coefficient matrix and $X$ represents the factor loading matrix after rotation.

FA is adopted to solve the problem of "Dimensional disaster" while most of the original information are remained and avoid the influence of multicollinearity on the prediction results.

\subsection{Comparison of the Methods}

The machine learning methods used in LSP follow an important assumption that conditions similar to historical landslide locations will be more likely prone to failures again in the future [45]. Among the methods applied in this study, the LR model and FCM are based on Bernoulli distribution and fuzzy theory, respectively. LR model is suitable for both classification and regression, which has been successfully applied in the fields of medicine, economy and biology. Similarly, the application of FCM is also extensive. As for limitations, LR model is sensitive to the collinearity between independent variables, which is also one of the reasons for its unsatisfactory results compared to other NMLM. The location and number of initial cluster centers needed to be determined first for FCM. FCM and FA belong to an unsupervised learning method that models without priori conditions and usually performs not as well as the supervised learning method. LR models are conducted with the use of labeled samples and it belongs to supervised learning.

As the representatives of TMLM, three methods have their own merits and limitations based on their respective assumptions. Therefore, it is recommended to combine two or even three methods to compensate for the inherent limitations of a single model.

\subsection{Model Performance}

A scientific model needs to be verified properly before generalizing and the dataset should be divided into two parts as training-testing sets. In earlier studies, the single random division was common, which divides the data into training and validation set in a certain proportion [46]. However, a more robust verification method should be recommended and fivefold cross-validation is applied in the study [47]. Three other indexes as sensitivity, specificity and accuracy were utilized to evaluate the performance of models. Finally, standard errors were used to determine the errors associated with the susceptibility predictions for each model. The equations involved are shown as follow:

$$
\begin{gathered}
\text { Accuracy }=\frac{T P+T N}{T P+T N+F P+F N} \\
\text { Sensitivity }=\frac{T P}{T P+F N} \\
\text { Specificity }=\frac{T N}{F P+T N}
\end{gathered}
$$

where True Positive $(T P)$ and True Negative $(T N)$ is the number of correctly predicted landslides and non-landslides, respectively; False Positive (FP) and False Negative (FN) are the incorrect number of landslide and non-landslides samples, respectively.

Receiver Operating Characteristic (ROC) is constructed by TP (sensitivity) and FP (1-specificity) ratios. The area under the cure (AUC) is also applied to evaluate model performance. For a classifier with very poor performance, its ROC curve will appear as a straight line with a $45^{\circ}$ oblique finger at the upper right corner, while for a classifier with better performance, its ROC curve will be closer to the upper left corner of the image. That is, the AUC under the image will be larger and the higher the AUC value indicates the better model performance. The correlation between predictive power and AUC can be quantified as: excellent (0.9-1), excellent (0.8-0.9), good (0.7-0.8), average (0.6-0.7), 
poor (0.5-0.6). If the AUC value is 0.5, the model has no application value. The flow chart of the study was shown in Figure 5.

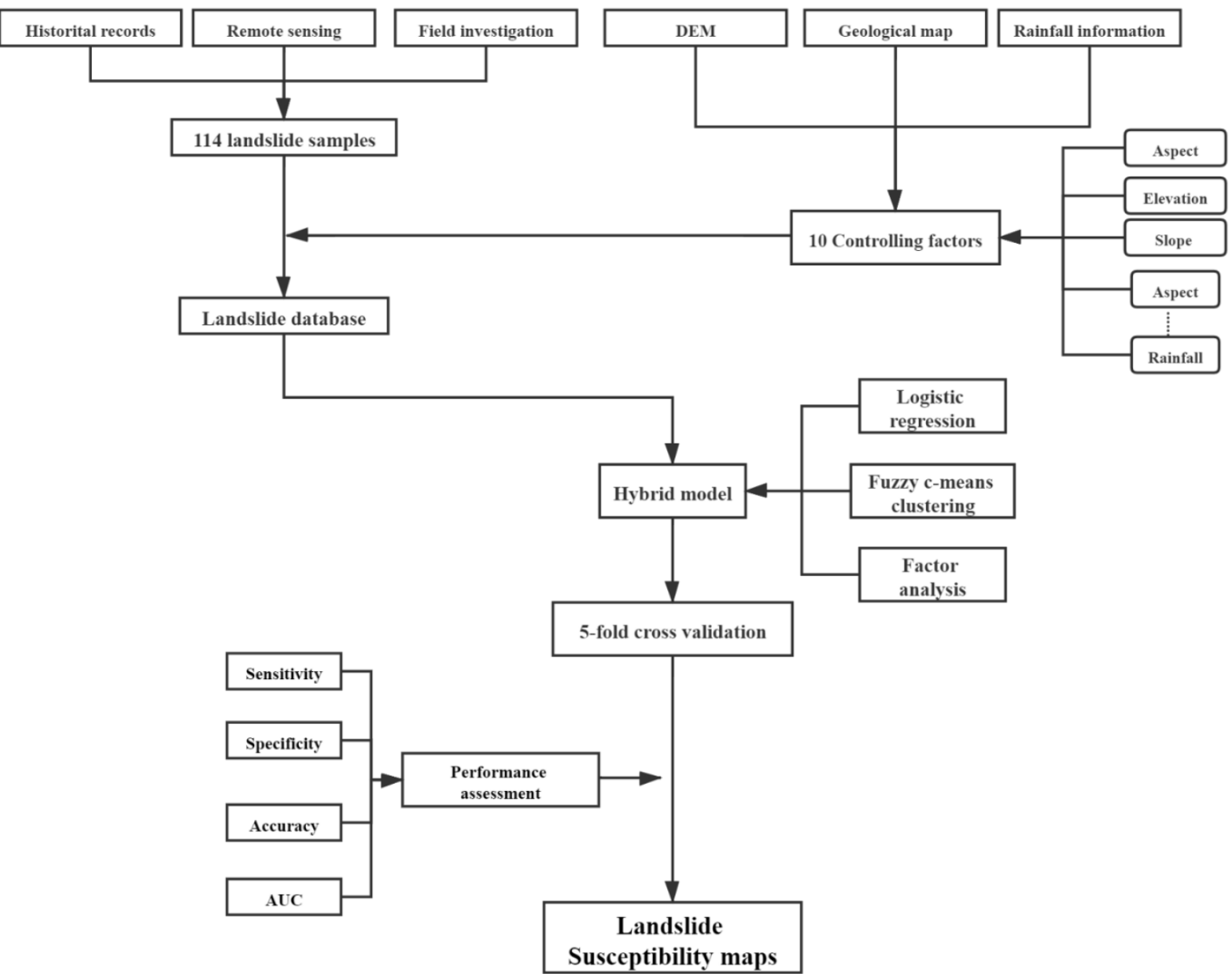

Figure 5. Flow chart of the methodology applied in the study.

\section{Results and Validation}

Z-score was applied to standardize the data and eliminate the impact of different dimensions (units), which was also provided by SPSS.

\subsection{LR Model}

The LR model was performed by adopting the stepwise forward method in SPSS software for screening of conditioning factors. The significant values of all variables retained in the last step of the analysis were less than 0.05 , so no variables were added. The model finally selected the factors that have a significant influence on the model fitting by slope angle and roundness after several iterations.

The coefficient of slope angle was the largest as 0.619 , which illustrated that it had the greatest influence on the occurrence of a landslide. In addition, the regression coefficients of the two factors were all greater than zero, indicating a positive correlation between the occurrence of landslide and the factors. The obtained LR equations are shown as follow:

$$
\operatorname{Logit}(p)=\ln \left(\frac{p}{1-p}\right)=-1.322+0.619 \times F 4+0.488 \times F 10
$$

where $p$ is the probability of a landslide.

Table 2 shows that the Wald chi-square (Wald) value of slope (22.55) was higher than roundness (14.89), which indicated more importance for explaining the occurrence of landslide [41]. SPSS also provides the statistical indexes that reflect the goodness of 
fitting of the model: Cox and Snell $\mathrm{R}$ square values $\left(\mathrm{CSR}^{2}\right)$ and Nagelkerke $\mathrm{R}$ square $\left(\mathrm{NR}^{2}\right)$. The values of $\mathrm{CSR}^{2}$ and $\mathrm{NR}^{2}$ indicate that the independent variables can explain the dependent variables for which these values are $66.2 \%$ and $77.6 \%$ respectively. Table 3 shows the predicted accuracy of landslide (sensitivity) as $69.15 \%$ and that of non-landslide (specificity) as $76.26 \%$. Consequently, the overall predicted accuracy was $77.16 \%$ and the value of AUC was 0.745 .

Table 2. Regression coefficients of the LR model.

\begin{tabular}{cccc}
\hline Factor & B & S.E & Wals \\
\hline Slope angle (F4) & 0.619 & 0.124 & 22.55 \\
Roundness (F10) & 0.488 & 0.112 & 14.891 \\
Constant & -1.322 & 0.126 & 13.594 \\
\hline
\end{tabular}

Note: $\mathrm{B}=$ logistic coefficient; $\mathrm{S} . \mathrm{E}=$ standard error of estimation; Wals = Wald statistic.

Table 3. Statistics indexes and AUC value of the LR model.

\begin{tabular}{cccccc}
\hline $\mathbf{C S R}^{2}$ & $\mathbf{N R}^{2}$ & Accuracy & Sensitivity & Specificity & AUC \\
\hline 0.662 & 0.776 & 77.16 & 69.15 & 76.26 & 0.745 \\
\hline
\end{tabular}

\subsection{FCM Coupled with LR Model}

The exponent $\left(\mathrm{V}_{\mathrm{cs}}\right)$ is the ratio of the degree of compactness to dispersion and the greater $\mathrm{V}_{\mathrm{cs}}$ value indicates the better clustering effect. Accordingly, the optimal number of clustering was 4 (Figure 6) while the cluster results are shown in Table 4.

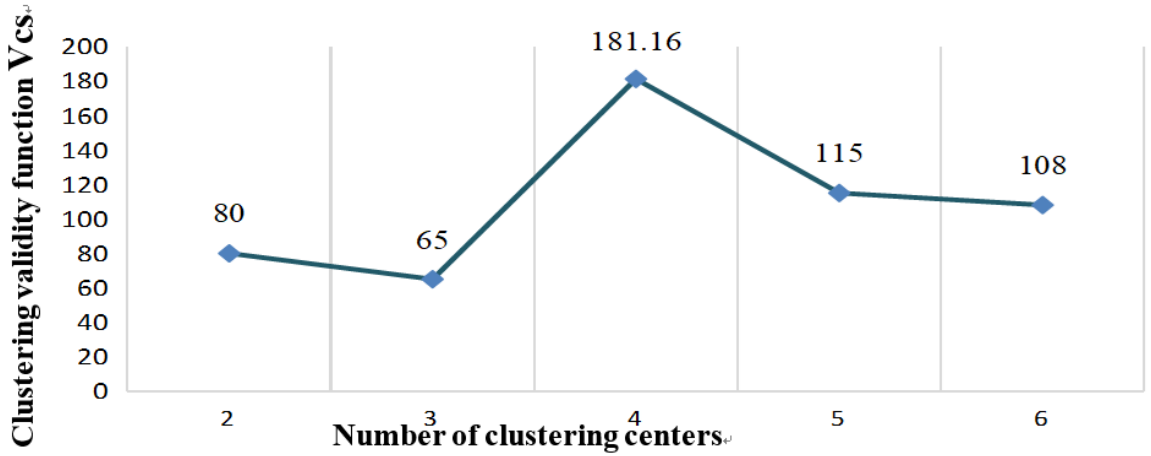

Figure 6. Clustering validity function $\mathrm{V}_{\mathrm{cs}}$.

Table 4. Clustering results of 503 catchments.

\begin{tabular}{cccc}
\hline Category & $\mathbf{0}$ & $\mathbf{1}$ & Total \\
\hline I & 88 & 31 & 119 \\
II & 132 & 24 & 156 \\
III & 55 & 21 & 76 \\
IV & 114 & 38 & 152 \\
Total & 389 & 114 & 503 \\
\hline
\end{tabular}

Different samples needed different factors and coefficients for fitting LR model (Table 5), which further identify the major factors of different clusters after clustering. For the first model, elevation and topographic wetness index were selected as main factors and the coefficients were all positive. However, the coefficient of distance to the stream was negative as -1.757 . For the second model, maximum rainfall of 7 days and plan curvature were determined as the major factors, the coefficients of which was 0.852 and 0.588 , respectively. In the third model, plan curvature and distance to stream were selected 
again, but the sign of coefficients were opposite as -0.477 and 0.322 , respectively. In the fourth model, roundness was chosen as the only fitting factor and the coefficient was 0.354 .

Table 5. Regression coefficients of each LR model.

\begin{tabular}{ccccc}
\hline Parameters/Coefficients & Model I & Model II & Model III & Model IV \\
\hline Maximum 7 days & 0 & 0.852 & 0 & 0 \\
rainfall $(F 1)$ & 0 & 0 & 0 & 0 \\
Distance to road $(F 2)$ & 2.931 & 0 & 0 & 0 \\
Elevation $(F 3)$ & 0 & 0 & 0 & 0 \\
Slope angle $(F 4)$ & 0 & 0.588 & -0.477 & 0 \\
Plan curvature $(F 5)$ & 0 & 0 & 0 & 0 \\
Profile curvature $(F 6)$ & 0.966 & 0 & 0 & 0 \\
Topographic wetness & 0 & 0 & 0 & 0 \\
index (F7) & -1.757 & 0 & 0.322 & 0 \\
Distance to fault $(F 8)$ & 0 & 0 & 0 & 0.354 \\
Distance to stream $(F 9)$ & -2.121 & -1.867 & -1.171 & -1.233 \\
Roundness $(F 10)$ & & & &
\end{tabular}

The hybrid model showed a better performance with the sensitivity, specificity and accuracy values of $73.81 \%, 85.77 \%$ and 84.89 , respectively (Table 6 ), which were all higher than that of LR model (Table 3). Besides, four models were established after clustering performed well with sensitivity values ranging from $71.28 \%$ to $74.88 \%$ and specificity values from $82.35 \%$ to $88.77 \%$.

Table 6. Statistical indexes and AUC value of the hybrid model.

\begin{tabular}{cccccc}
\hline & Model I & Model II & Model III & Model IV & Total (\%) \\
\hline Sensitivity (\%) & 74.88 & 71.28 & 74.18 & 72.30 & 73.81 \\
Specificity (\%) & 86.66 & 84.84 & 82.35 & 88.66 & 85.77 \\
Accuracy (\%) & 85.24 & 82.33 & 84.23 & 86.11 & 84.89 \\
\hline
\end{tabular}

\subsection{FA Coupled with LR Model}

The principal components were generated by FA to solve the problems of multiple linearities and information loss. The first seven factors $(C 1, C 2, C 3, C 4, C 5, C 6, C 7)$ were extracted and explained $90.231 \%$ of the total variance (Table 7 ). The contribution rate of the first three factors was relatively large as $45.726 \%, 15.794 \%$ and $10.979 \%$, respectively among them. According to the correlation coefficient of each common factor (Table 7), the first common factor (C1) mainly highlighted the information of profile curvature and elevation, which have reflected the topographic conditions for the development of landslide. Similarly, the second and the third common factor mainly highlighted the information of distance to road and distance to stream, respectively. The scoring functions were determined (Equation (11)) and LR model was established using five common factors scores (C1-C5) as independent variables. Accordingly, Equation (13) restored the relationship between the 10 conditioning factors and the occurrence of landslides. The coefficients of F1, F4, F5 and F7 were negative, which were not conducive to the occurrence of landslide. The coefficients of F6 and F10 were 0.702 and 0.706 , respectively, both of which are greater than 0.7 .

The introduction of FA simplifies the information carried by the original 10 conditioning factors into five common factors, achieving effective dimensionality reduction and retaining most of the information. 
Table 7. The correlation coefficients between principal components and original variables.

\begin{tabular}{cccccc}
\hline Factor & C1 & C2 & C3 & C4 & C5 \\
\hline Maximum 7 days rainfall $(F 1)$ & -0.469 & -0.657 & 0.155 & -0.066 & 0.059 \\
Distance to road $(F 2)$ & -0.019 & 0.921 & 0.028 & -0.018 & 0.036 \\
Elevation $(F 3)$ & 0.814 & 0.475 & 0.181 & -0.101 & 0.042 \\
Slope angle $(F 4)$ & -0.020 & -0.029 & 0.125 & 0.974 & -0.004 \\
Plan curvature $(F 5)$ & -0.128 & -0.003 & -0.949 & -0.139 & -0.049 \\
Profile curvature $(F 6)$ & 0.915 & 0.190 & 0.038 & 0.106 & 0.116 \\
Topographic wetness index $(F 7)$ & -0.846 & -0.076 & 0.067 & -0.060 & -0.044 \\
Distance to fault (F8) & 0.783 & 0.016 & 0.330 & -0.210 & 0.063 \\
Distance to stream (F9) & 0.555 & 0.650 & 0.817 & -0.116 & 0.083 \\
Roundness (F10) & 0.120 & 0.029 & 0.050 & -0.004 & 0.988 \\
Contribution rate $(\%)$ & 45.726 & 15.794 & 10.979 & 9.449 & 8.233 \\
Accumulative contribution $(\%)$ & 45.726 & 61.52 & 72.499 & 81.998 & 90.231 \\
\hline
\end{tabular}

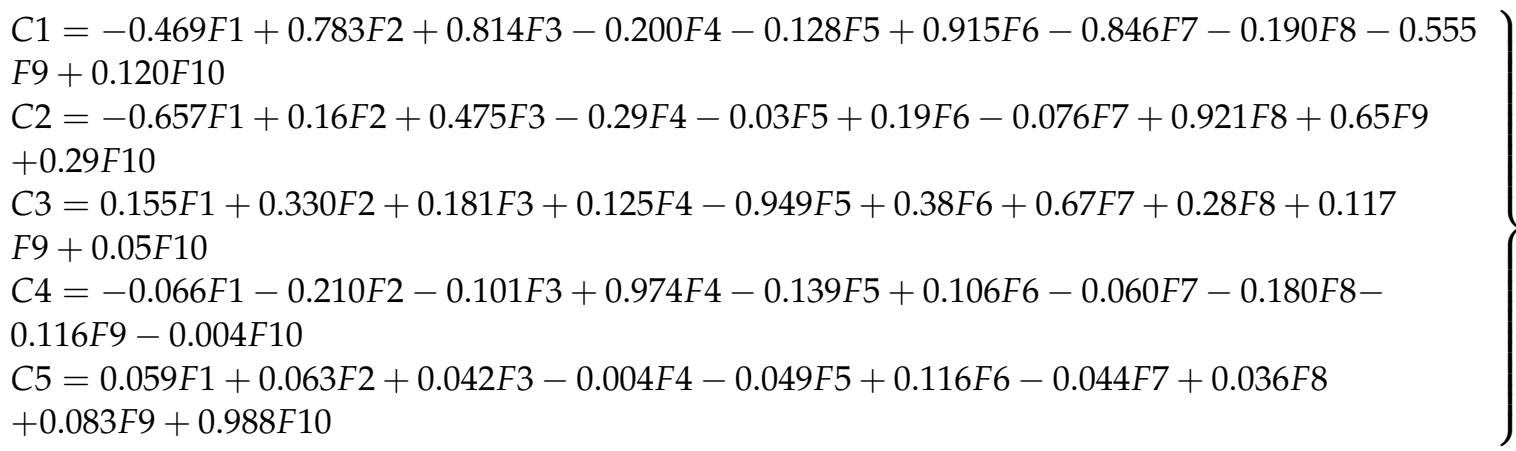

where $C 1$ to $C 5$ are the first to fifth principal components.

$C 1$ and $C 5$ were selected into the regression equation (Table 8 ) and the equation was:

$$
\ln \left(\frac{p}{1-p}\right)=-1.371+0.692 \times C 1+0.61 \times C 5
$$

Table 8. The regression coefficients of common factors in LR model.

\begin{tabular}{cccc}
\hline Common Factors & B & S.E & Wals \\
\hline C1 & 0.692 & 0.366 & 9.016 \\
C5 & 0.61 & 0.323 & 8.241 \\
Constant & -1.371 & 0.311 & 8.715 \\
\hline
\end{tabular}

Combining Equations (9) and (10), a multinomial LR equation can be obtained as:

$$
\begin{aligned}
\ln \left(\frac{p}{1-p}\right)= & -1.372-0.289 \times F 1+0.582 \times F 2+0.588 F 3-0.016 \times F 4-0.119 \times F 5+ \\
& 0.702 \times F 6-0.616 \times F 7+0.009 \times F 8+0.428 \times F 9+0.716 \times F 10
\end{aligned}
$$

The established model had a high degree of fit (Table 9), but it was slightly lower than the LR model (Table 2). The accuracy reached $83.29 \%$ while the value of sensitivity was $73.11 \%$ and specificity was $84.79 \%$ (Table 9 ) which was significantly improved compared with LR model (Table 3). In addition, the value of Kaiser-Meyer-Olkin (KMO) was 0.789, which indicated that the correlation between variables was obvious and suitable for FA.

Table 9. Statistical indexes and AUC value of the hybrid model.

\begin{tabular}{ccccccc}
\hline$-\mathbf{2 L L}$ & $\mathbf{C S R}^{2}$ & $\mathbf{N R}^{2}$ & KMO & Accuracy & Sensitivity & Specificity \\
\hline 69.791 & 0.345 & 0.698 & 0.789 & 83.29 & 73.11 & 84.79 \\
\hline
\end{tabular}




\subsection{FCM, FA Coupled with LR Model}

A model combining three statistical methods FCM, FA, and LR was finally established. Firstly, the cluster analysis was carried out, then the FA was performed on each clustering sample and finally the LR model was established.

Five common factors were involved in the first and second model while four for the third and fourth model (Table 10). LR equations were similarly established respectively with the regression coefficients of common factors (Table 11).

Table 10. Contribution rates of common factors in four models.

\begin{tabular}{cccccc}
\hline \multicolumn{1}{c}{ Factors } & Models & Model I & Model II & Model III & Model IV \\
\hline & C1 & 39.244 & 46.216 & 47.293 & 48.432 \\
C2 & 14.147 & 15.274 & 18.529 & 14.424 \\
C3 & 11.889 & 10.665 & 11.911 & 10.941 \\
C4 & 10.02 & 8.808 & 9.476 & 9.836 \\
C5 & 7.245 & 7.388 & 0 & 0 \\
Accumulative contribution (\%) & 85.544 & 88.352 & 87.209 & 86.633 \\
\hline
\end{tabular}

Table 11. The regression coefficients of common factors in LR model.

\begin{tabular}{cccccc}
\hline Factors & Models & Model I & Model II & Model III & Model IV \\
\hline C1 & & 0 & 0 & 0.587 & 0 \\
C2 & 0.59 & 0 & 0 & 0 \\
C3 & 0 & 0 & 0 & 0 \\
C4 & 0 & 0.421 & 0 & 0.349 \\
C5 & 0 & 0 & 0 & 0 \\
Constant & -1.212 & -1.825 & -1.347 & -1.248 \\
\hline
\end{tabular}

The coefficients and symbols corresponding to each factor in different models varied (Equation (14)), which not only highlighted the difference of major factors among different samples, but also retained most of the information of the original data. For the first model, the coefficients of $F 2, F 3$ and $F 9$ were relatively large as $0.396,0.386$ and 0.208 , respectively. Additionally, the coefficients of $F 1$ and $F 7$ were negative as -0.526 and -0.061 , respectively. Similarly, the coefficients of $F 4$ and $F 6$ in the second model were 0.411 and 0.125 , respectively. The coefficients of $F 2, F 3, F 5, F 7, F 8, F 9$ and $F 10$ were negative and the coefficients of $F 3, F 8$ and $F 9$ in the third model were $0.477,0.559$ and 0.543 , respectively. The coefficients of $F 1, F 4$ and $F 7$ were negative. For the fourth model, the coefficient of $F 10$ was relatively large as 0.343 . All the models passed KMO test, but the values were lower than those of FA coupled with LR model (Table 9). The accuracy reached to $88.01 \%$ while the values of sensitivity and specificity were $79.85 \%$ and $89.58 \%$, respectively (Table 12 ), which was exceeded from the other three models.

$$
\begin{aligned}
& \ln \left(\frac{p}{1-p}\right)=-1.212-0.526 \times F 1+0.396 \times F 2+0.386 \times F 3+0.034 \times F 4-0.007 \times F 5+ \\
& 0.186 \times F 6-0.061 \times F 7+0.095 \times F 8+0.208 \times F 9-0.004 \times F 10 \\
& \ln \left(\frac{p}{1-p}\right)=-1.825+0.012 \times F 1-0.037 \times F 2-0.037 \times F 3+0.411 \times F 4-0.062 \times F 5 \\
&+ 0.125 \times F 6-0.029 \times F 7-0.016 \times F 8-0.041 \times F 9-0.078 \times F 10 \\
& \ln \left(\frac{p}{1-p}\right)=-1.347-0.534 \times F 1+0.036 \times F 2+0.477 \times F 3-0.018 \times F 4+0.029 \times F 5+ \\
& 0.224 \times F 6-0.197 \times F 7+0.559 \times F 8+0.543 \times F 9+0.004 \times F 10 \\
& \ln \left(\frac{p}{1-p}\right)=-1.248-0.008 \times F 1+0.044 \times F 2+0.023 \times F 3-0.012 \times F 4-0.008 \times F 5+
\end{aligned}
$$


Table 12. Statistical indexes and AUC value of the hybrid model.

\begin{tabular}{ccccc}
\hline Statistical Indexes & Model I & Model II & Model III & Model IV \\
\hline -2LL & 42.595 & 40.453 & 28.913 & 38.923 \\
CSR $^{2}$ & 0.709 & 0.645 & 0.682 & 0.693 \\
NR $^{2}$ & 0.617 & 0.723 & 0.754 & 0.776 \\
KMO & 0.600 & 0.762 & 0.711 & 0.742 \\
Sensitivity (\%) & 76.74 & 88.07 & 78.62 & 78.26 \\
Specificity (\%) & 87.91 & 91.92 & 90.24 & 88.24 \\
Accuracy (\%) & 85.37 & 91.59 & 87.76 & 86.53 \\
\hline
\end{tabular}

\subsection{Validation and Comparison}

The generalization performance of the proposed models should be validated by the test data. Table 13 shows that the accuracy of three hybrid models was better than that of LR model. Besides, the model combing with FCM, FA and LR also performed the best with the highest value of accuracy, sensitivity and specificity, which was $85.25 \%, 74.96 \%$ and $86.21 \%$, respectively.

Table 13. Model performance using validation data.

\begin{tabular}{|c|c|c|c|c|c|c|}
\hline \multirow[b]{2}{*}{ Index } & \multicolumn{3}{|c|}{ Training } & \multicolumn{3}{|c|}{ Validation } \\
\hline & Accuracy & Sensitivity & Specificity & Accuracy & Sensitivity & Specificity \\
\hline Models & $(\%)$ & $(\%)$ & $(\%)$ & $(\%)$ & $(\%)$ & $(\%)$ \\
\hline LR model & 77.66 & 67.45 & 78.2 & 77 & 65.52 & 72.55 \\
\hline FCM coupled with LR model & 83.63 & 72.61 & 85.15 & 77.63 & 67.6 & 78.4 \\
\hline FA coupled with LR model & 83.29 & 73.11 & 84.79 & 80.72 & 71.79 & 81.47 \\
\hline FCM, FA coupled with LR model & 88.01 & 79.85 & 89.58 & 85.25 & 74.96 & 86.21 \\
\hline
\end{tabular}

The AUC values of the three hybrid models were also higher than the single LR model, which indicated that the establishment of the hybrid model was beneficial to predict landslide in the study area (Figure 7). The model combining with FCM, FA and LR achieved the highest value of AUC as 0.827 , followed by the model coupled with FA and LR as 0.782 (Table 14). It indicated that the dimensionality reduction and clustering improve the performance of LR model. The performance of models in validation turned down in comparison to the results from training data. The accuracy of the model combining with FCM and LR dropped obviously, which indicated over-fitting and limited generalization. Cluster analysis reduces the sample size for modeling and FA solves the "dimensional disaster". The sample size varies greatly based on the size of the study area. The dimension also varies but it is not that obvious because the conditioning factors applied for modeling in LSP are relatively stable. On the other hand, there is a slight decrease in the values of AUC compared to the training dataset. The errors related to probability estimation were negligible as the standard error were all less than 0.05 (Table 15). 

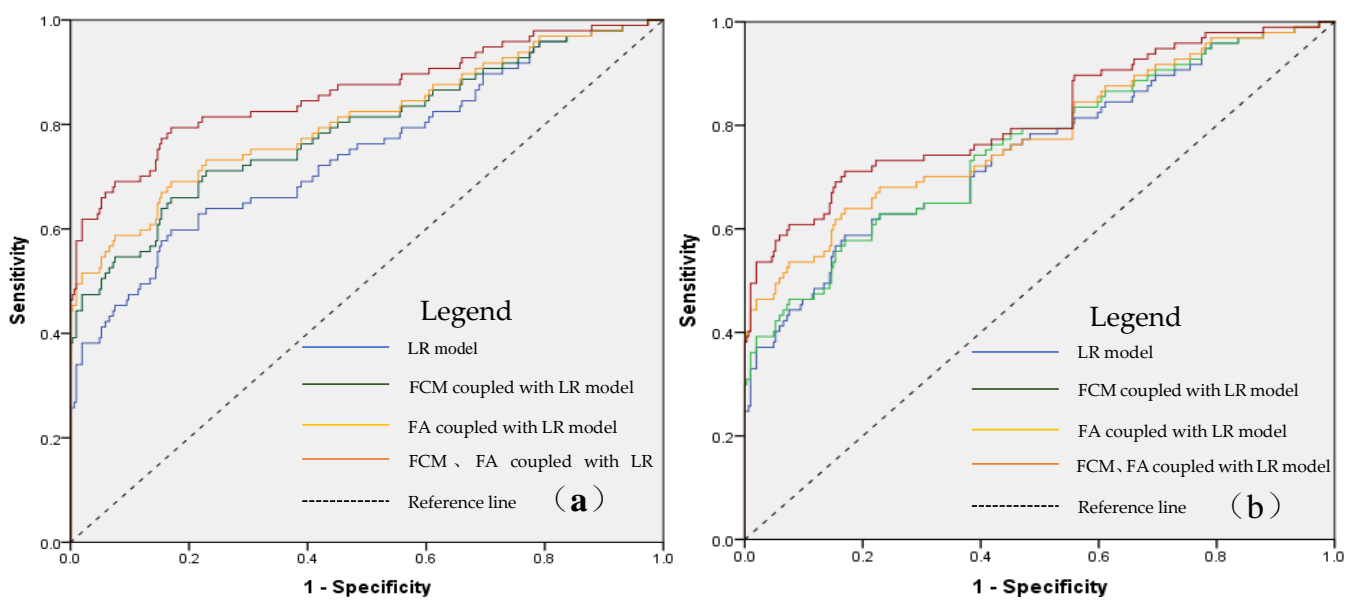

Figure 7. ROC cure for four models. (a) Success rate curve for training data; (b) prediction rate curve for validation data.

Table 14. AUC values of models using validation data.

\begin{tabular}{ccc}
\hline Model & AUC for Training & AUC for Validation \\
\hline LR model & 0.755 & 0.736 \\
FCM coupled with LR model & 0.788 & 0.744 \\
FA coupled with LR model & 0.818 & 0.782 \\
FCM, FA coupled with LR model & 0.862 & 0.827 \\
\hline
\end{tabular}

Table 15. Standard errors of each model.

\begin{tabular}{cc}
\hline Model & Standard Errors \\
\hline LR model & 0.033 \\
FCM coupled with LR model & 0.031 \\
FA coupled with LR model & 0.021 \\
FCM, FA coupled with LR model & 0.031 \\
\hline
\end{tabular}

The trained and validated models were applied to the whole study area, the probability of landslide (p), which is also known as landslide susceptibility index (LSI) was calculated for each unit and the results were imported into ArcGIS 10.2.1 platform. The landslide susceptibility map was reclassified into several classes based on the LSI and class probabilities either with equal interval or natural break are most common. To compare the result of the maps more expediently, the study area was classified into five categories of landslide susceptibility levels as very low (0 0.2), low (0.2 0.4), moderate (0.4 0.6), high (0.6 0.8) and very high $(0.8 \sim 1.0)$ based on equal spacing principle and the results were shown in Figure 8. The maps should follow an important principle that the observed landslides should be more likely to appeared in the high susceptibility area. Therefore, the landslide points would be better predicted in the dark area (orange or red) and the non-landslide points were in light area (green). Therefore, the map predicted by FCM, FA coupled with LR model was the most reasonable. The percentage of moderate class accounts the smallest proportion (10.64\%) while very low (45.62\%) and high class (8.67\%) accounts the biggest proportion compared to other models (Figure 9). 

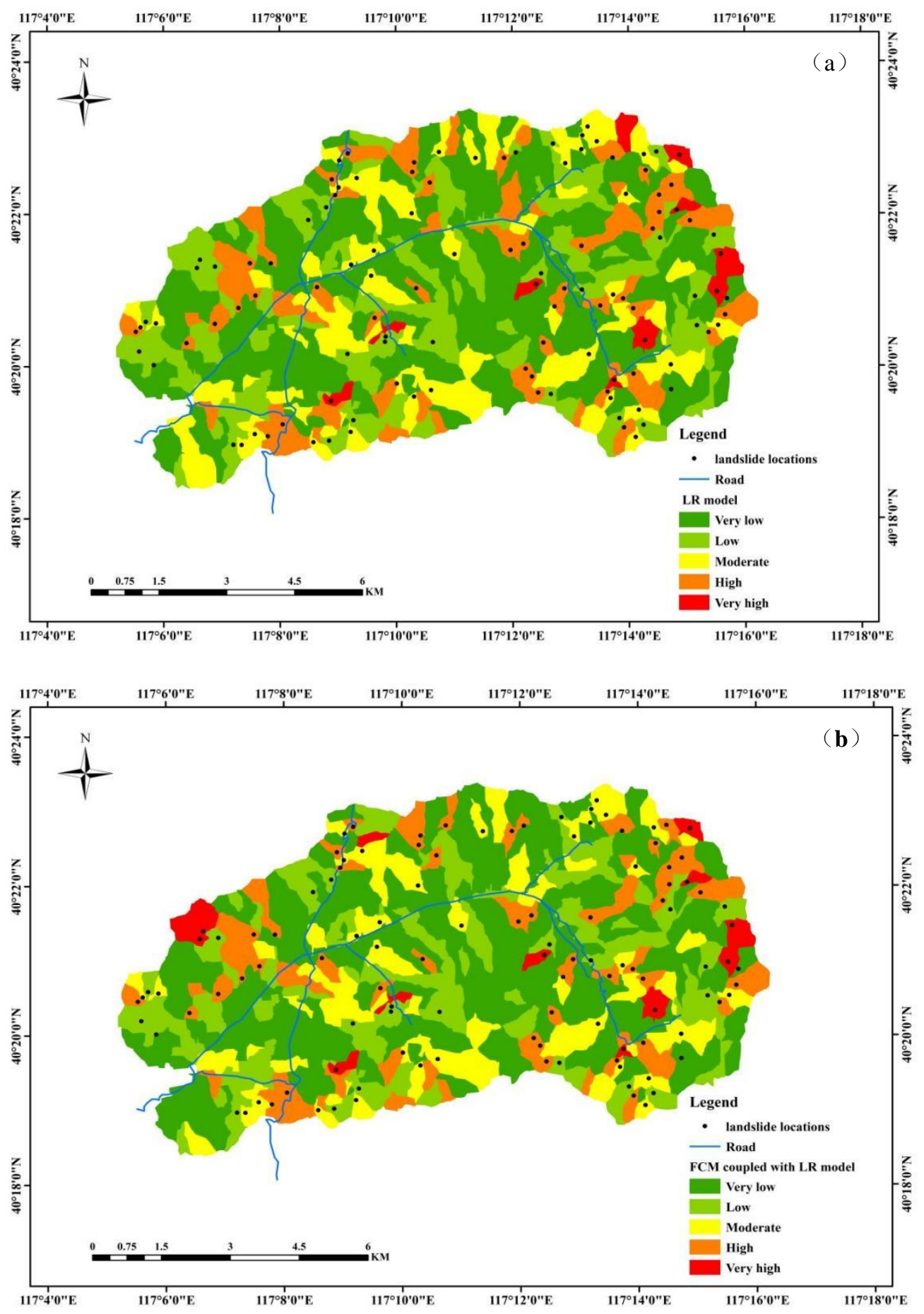

Figure 8. Cont. 


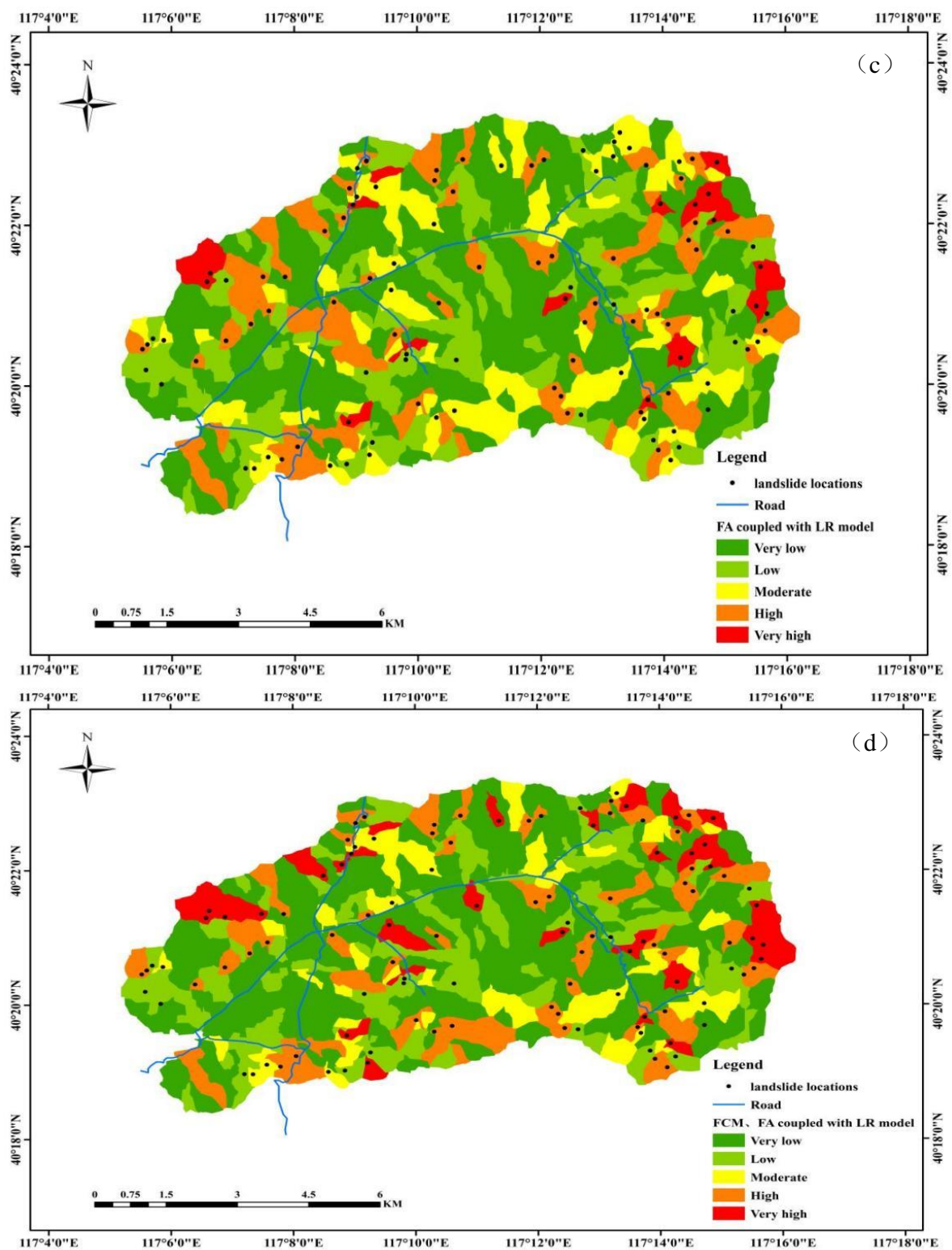

Figure 8. Landslide susceptibility maps: (a) LR model; (b) FCM coupled with LR model; (c) FA coupled with LR model; (d) FCM, FA coupled with LR model.

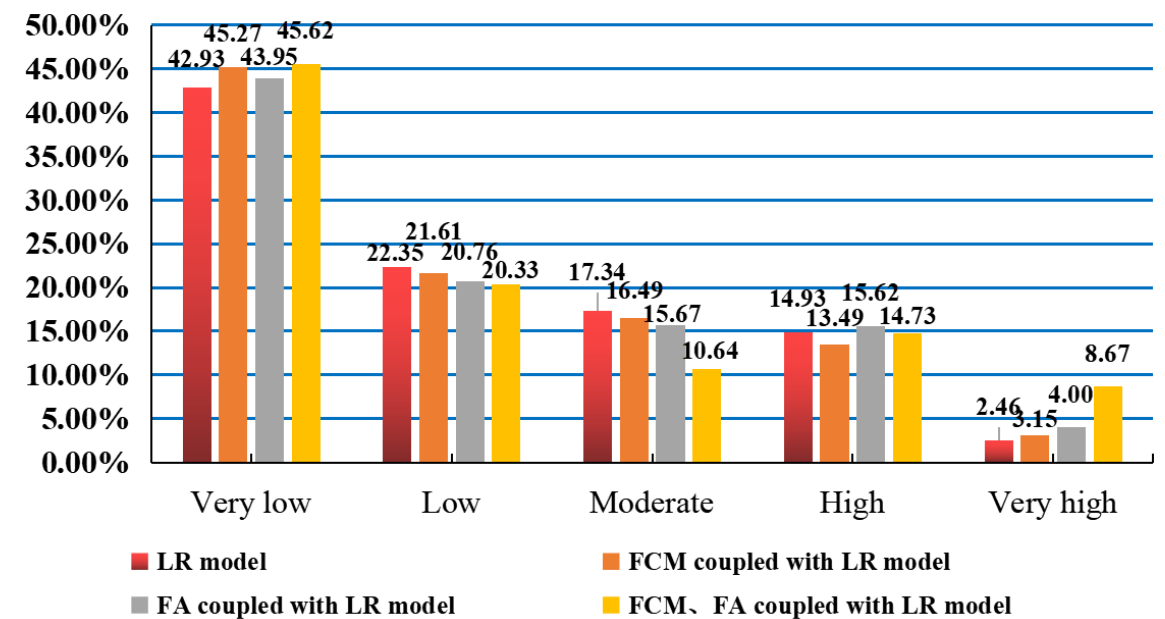

Figure 9. The percentage of the different susceptibility classes. 


\section{Discussion}

\subsection{Comparison of TMLM and NMLM}

TMLM have been applied in LSP for many years and showed their own advantages and drawbacks [48]. Recently, NMLM evolved from statistical methods has been popular due to their ability in data processing and satisfactory results [49-55]. NMLM as random forest and support vector machine was applied in LSP and the accuracy reached 90\%, the value of AUC exceeds 0.9 [56,57]. The quantity of samples is the key for NMLM because the application of NMLM emphasizes optimization and usually involves several hyper-parameters needed to be tuned. Actually, the samples are limited, especially for the county-level study area. It is hard to avoid the problem of over-fitting for NMLM without enough data. On the contrary, TMLM focuses on inference and mathematical equations based on certain assumptions, which are easier to implement and understandable. Logistic regression can find an accurate fitting function to define the nonlinear relationship between landslide or non-landslide and a set of hazard-pregnancy factors, and there are almost no "hyperparameters" that need to be tuned. Therefore, the models applied in the current study are suitable for LSP, especially for the county-level study area. The visualization of the final equation of the logistic regression model, when combined with cluster analysis and factor analysis, makes the results easier to understand. The hybrid model discussed in the current study also performed well in terms of accuracy but is importantly more comprehensible and operational.

\subsection{The Necessity of Model Integration}

Although previous researchers have applied LR model, FCM and FA in susceptibility prediction of geological disasters for many times [45], few studies have combined them for an improved model. There are certain limitations in a model established by a single method either NMLM or TMLM. Random forest is one of the famous ensemble learning algorithms [58]. Common ensemble algorithms as Bagging and Boosting aim to constructed a strong classifier by means of combining several weak classifiers [59-61]. In the current study, the hybrid models aim to make up for the deficiencies considering that TMLM have their own concerns. The integration of different methods is flexible but purposeful. LR model lacks pertinence because the main conditioning factors of different types of samples are different, even if they are the same, the relative importance also varies greatly. The introduction of FCM solves the problem and is conducive to further research and prevention of disasters. The accuracy of the three hybrid models was higher than that of the single LR model and the AUC results also illuminated that the establishment of the hybrid model was effective.

There is no clear agreement on the selection of the best model for many years as the performance vary for the different study area. It is common to apply multiple methods to the same study area for comparison to find out the best model according to unified standards such as the AUC. However, new methods are constantly emerging and not only the comparison but the effort for a universal model also counts. Therefore, it is necessary to explore a universally accepted model which collects the advancement of several methods. Besides, producing accurate LSP results is important but should not be the only consideration.

In the past, the stepwise forward method is applied to filter the variables and the variables are left by the last step with the significance values less than 0.05 [57]. Usually, few variables will be retained in this way and the information that has an important impact on the default may lose. Accordingly, it is unreliable for LR model to recognize the predisposing factors responsible for the occurrence of landslides and sometimes even draw conclusions that are contrary to past experience. However, if all variables are retained forcibly, the collinearity between variables cannot be avoided, resulting in poor model fitting and low prediction accuracy. The LR model based on FA avoided the influence of the multi-collinearity problem and improved the reliability of the regression coefficient under the condition of retaining the original data information as much as possible. Moreover, 
the retention of most of the original information enhances the analyticity and persuasion of the equation. Previous studies have applied FCM and FA in LSP and the results obtained are not as good as LR model mainly because FCM and FA belong to unsupervised learning and the prior conditions cannot be fully utilized [61-64]. Therefore, the hybrid model established in this study is reasonable and purposeful, combining the advantages of supervised and unsupervised learning.

\section{Conclusions}

In this study, complementary models based on FCM, FA and LR were explored and discussed to find out a suitable model for LSP in a county-level study area, which has better accuracy, convenience and analyticity. The following conclusions can be drawn from the present study.

The introduction of FCM and FA compensates for the deficiencies of the LR model to some extent, and the hybrid models performed better in terms of accuracy and generalization ability. The performance of TMLM can be improved by combining with the specific methods to obtain better performance as NMLM. Secondly, the hybrid model is able to retain the majority of the information and identify the main conditioning factors of different types of data, so the credibility and communicating ability of the model are enhanced. The combination of models should be more flexible and purposeful and the evaluation standards should be expanded, and not solely focused on accuracy. Both dimension reduction and sample size should be considered in modeling. However, future work need to explored as flow:

1. The models could be compared to the new machine learning algorithms;

2. More diverse methods and combinations need to be discussed further.

Author Contributions: Han Hu: writing, methodology; Changming Wang: reviewing and editing; Zhu Liang: software and validation; Ruiyuan Gao: methodology; Bailong Li: investigation. All authors have read and agreed to the published version of the manuscript.

Funding: This work was founded by the National Natural Science Foundation of China (Grant No. 41972267, 41977221, and 41572257).

Institutional Review Board Statement: Not applicable.

Informed Consent Statement: Not applicable.

Data Availability Statement: Data sharing not applicable.

Conflicts of Interest: The authors declare no conflict of interest.

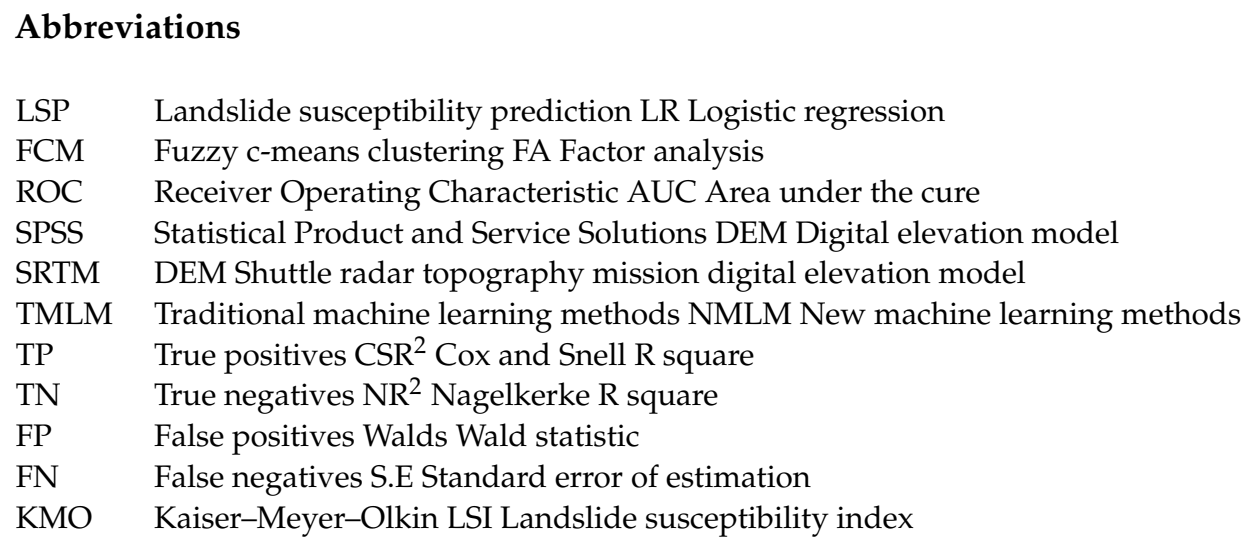




\section{References}

1. Huang, Y.; Zhao, L. Review on landslide susceptibility mapping using support vector machines. CATENA 2018, 165, 520-529. [CrossRef]

2. Fan, X.; Scaringi, G.; Korup, O.; West, A.J.; van Westen, C.J.; Tanyas, H.; Hovius, N.; Hales, T.C.; Jibson, R.W.; Allstadt, K.E.; et al. Earthquake-induced chains of geologic hazards: Patterns, mechanisms, and impacts. Rev. Geophys. 2019, 57, 421-503. [CrossRef]

3. Ni, H.; Zheng, W.; Li, Z.; Ba, R. Recent catastrophic debris flows in Luding county, SW China: Geological hazards, rainfall analysis and dynamic characteristics. Nat. Hazards 2010, 55, 523-542. [CrossRef]

4. Wang, Z.; Liu, Q.; Liu, Y. Mapping Landslide Susceptibility Using Machine Learning Algorithms and GIS: A Case Study in Shexian County, Anhui Province, China. Symmetry 2020, 12, 1954. [CrossRef]

5. Blais-Stevens, A.; Behnia, P. Debris flow susceptibility mapping using a qualitative heuristic method and Flow-R along the Yukon Alaska Highway Corridor, Canada. Nat. Hazards Earth Syst. Sci. 2016, 16, 449-462. [CrossRef]

6. Schilirò, L.; Cevasco, A.; Esposito, C.; Mugnozza, G.S. Shallow landslide initiation on terraced slopes: Inferences from a physically based approach. Geomat. Nat. Hazards Risk 2018, 9, 295-324. [CrossRef]

7. Aditian, A.; Kubota, T.; Shinohara, Y. Comparison of GIS-based landslide susceptibility models using frequency ratio, logistic regression, and artificial neural network in a tertiary region of Ambon, Indonesia. Geomorphology 2018, 318, 101-111. [CrossRef]

8. Shi, M.; Chen, J.; Song, Y.; Zhang, W.; Song, S.; Zhang, X. Assessing debris flow susceptibility in Heshigten Banner, Inner Mongolia, China, using principal component analysis and an improved fuzzy C-means algorithm. Bull. Int. Assoc. Eng. Geol. 2015, 75, 909-922. [CrossRef]

9. Liang, Z.; Wang, C.; Han, S.; Khan, K.U.J.; Liu, Y. Classification and susceptibility assessment of debris flow based on a semiquantitative method combination of the fuzzy C-means algorithm, factor analysis and efficacy coefficient. Nat. Hazards Earth Syst. Sci. 2020, 20, 1287-1304. [CrossRef]

10. Chen, W.; Peng, J.; Hong, H.; Shahabi, H.; Pradhan, B.; Liu, J.; Zhu, A.-X.; Pei, X.; Duan, Z. Landslide susceptibility modelling using GIS-based machine learning techniques for Chongren County, Jiangxi Province, China. Sci. Total Environ. 2018, 626, 1121-1135. [CrossRef] [PubMed]

11. Hong, H.; Liu, J.; Zhu, A.-X. Modeling landslide susceptibility using LogitBoost alternating decision trees and forest by penalizing attributes with the bagging ensemble. Sci. Total Environ. 2020, 718, 137231. [CrossRef]

12. Gao, R.; Wang, C.; Liang, Z.; Han, S.; Li, B. A Research on Susceptibility Mapping of Multiple Geological Hazards in Yanzi River Basin, China. ISPRS Int. J. Geo-Inf. 2021, 10, 218. [CrossRef]

13. Liang, Z.; Wang, C.; Duan, Z.; Liu, H.; Liu, X.; Khan, K.U.J. A Hybrid Model Consisting of Supervised and Unsupervised Learning for Landslide Susceptibility Mapping. Remote Sens. 2021, 13, 1464. [CrossRef]

14. Lin, Q.; Lima, P.; Steger, S.; Glade, T.; Jiang, T.; Zhang, J.; Liu, T.; Wang, Y. National-scale data-driven rainfall induced landslide susceptibility mapping for China by accounting for incomplete landslide data. Geosci. Front. 2021, 12, 101248. [CrossRef]

15. Armaș, I.; Gheorghe, M.; Silvaș, G. Shallow Landslides Physically Based Susceptibility Assessment Improvement Using InSAR. Case Study: Carpathian and Subcarpathian Prahova Valley, Romania. Remote Sens. 2021, 13, 2385. [CrossRef]

16. Sujatha, E.R. An integrated landslide susceptibility model to assess landslides along linear infrastructure for environmental management. Environ. Earth Sci. 2021, 80, 447. [CrossRef]

17. Liang, Z.; Wang, C.-M.; Zhang, Z.-M.; Khan, K.-U. A comparison of statistical and machine learning methods for debris flow susceptibility mapping. Stoch. Environ. Res. Risk Assess. 2020, 34, 1887-1907. [CrossRef]

18. Hu, X.; Huang, C.; Mei, H.; Zhang, H. Landslide susceptibility mapping using an ensemble model of Bagging scheme and random subspace-based naïve Bayes tree in Zigui County of the Three Gorges Reservoir Area, China. Bull. Int. Assoc. Eng. Geol. 2021, 80, 5315-5329. [CrossRef]

19. Wu, Y.; Ke, Y.; Chen, Z.; Liang, S.; Zhao, H.; Hong, H. Application of alternating decision tree with AdaBoost and bagging ensembles for landslide susceptibility mapping. CATENA 2019, 187, 104396. [CrossRef]

20. Li, W.; Fang, Z.; Wang, Y. Stacking ensemble of deep learning methods for landslide susceptibility mapping in the Three Gorges Reservoir area, China. Stoch. Environ. Res. Risk Assess. 2021. [CrossRef]

21. Hu, X.; Zhang, H.; Mei, H.; Xiao, D.; Li, Y.; Li, M. Landslide Susceptibility Mapping Using the Stacking Ensemble Machine Learning Method in Lushui, Southwest China. Appl. Sci. 2020, 10, 4016. [CrossRef]

22. Dou, J.; Yunus, A.P.; Bui, D.T.; Merghadi, A.; Sahana, M.; Zhu, Z.; Chen, C.-W.; Han, Z.; Pham, B.T. Improved landslide assessment using support vector machine with bagging, boosting, and stacking ensemble machine learning framework in a mountainous watershed, Japan. Landslides 2019, 17, 641-658. [CrossRef]

23. Merghadi, A.; Yunus, A.P.; Dou, J.; Whiteley, J.; ThaiPham, B.; Bui, D.T.; Avtar, R.; Abderrahmane, B. Machine learning methods for landslide susceptibility studies: A comparative overview of algorithm performance. Earth-Sci. Rev. 2020, $207,103225$. [CrossRef]

24. Liang, Z.; Wang, C.; Khan, K.U.J. Application and comparison of different ensemble learning machines combining with a novel sampling strategy for shallow landslide susceptibility mapping. Stoch. Environ. Res. Risk Assess. 2020, 35, 1243-1256. [CrossRef]

25. Li, X.; Chen, P.; Han, W.; Shi, H.; Yu, H. Application of factor analysis to debris flow risk assessment. Chin. J. Geol. Hazard Control. 2016, 27, 55-61. [CrossRef]

26. Tian, C.; Liu, X.; Wang, J. Geohazard susceptibility assessment based on CF model and Logistic regression models in Guangdong. Hydroge Eng. 2016, 43, 154-161. [CrossRef] 
27. Sezer, E.; Nefeslioglu, H.; Gokceoglu, C. An assessment on producing synthetic samples by fuzzy C-means for limited number of data in prediction models. Appl. Soft Comput. 2014, 24, 126-134. [CrossRef]

28. Verde, R.; Irpino, A. Multiple factor analysis of distributional data. arXiv 2018, arXiv:1804.07192.

29. Hussin, H.Y.; Zumpano, V.; Reichenbach, P.; Sterlacchini, S.; Micu, M.; van Westen, C.; Bălteanu, D. Different landslide sampling strategies in a grid-based bi-variate statistical susceptibility model. Geomorphology 2015, 253, 508-523. [CrossRef]

30. Carrara, A.; Cardinali, M.; Detti, R.; Guzzetti, F.; Pasqui, V.; Reichenbach, P. GIS techniques and statistical models in evaluating landslide hazard. Earth Surf. Process. Landf. 1991, 16, 427-445. [CrossRef]

31. Carrara, A.; Guzzetti, F.; Cardinali, M.; Reichenbach, P. Use of GIS Technology in the Prediction and Monitoring of Landslide Hazard. Nat. Hazards 1999, 20, 117-135. [CrossRef]

32. Palamakumbure, D.; Flentje, P.; Stirling, D. Consideration of optimal pixel resolution in deriving landslide susceptibility zoning within the Sydney Basin, New South Wales, Australia. Comput. Geosci. 2015, 82, 13-22. [CrossRef]

33. Reichenbach, P.; Rossi, M.; Malamud, B.D.; Mihir, M.; Guzzetti, F. A Review of Statistically-Based Landslide Susceptibility Models. Earth-Sci. Rev. 2018, 180, 60-91. [CrossRef]

34. Lombardo, L.; Tanyas, H.; Nicu, I.C. Spatial modeling of multi-hazard threat to cultural heritage sites. Eng. Geol. 2020, 277, 105776. [CrossRef]

35. DI, B.; Chen, N.; Cui, P.; Li, Z.; He, Y.; Gao, Y. GIS-based risk analysis of debris flow: An application in Sichuan, southwest China. Int. J. Sediment Res. 2008, 23, 138-148. [CrossRef]

36. Dou, J.; Yunus, A.P.; Xu, Y.; Zhu, Z.; Chen, C.-W.; Sahana, M.; Khosravi, K.; Yang, Y.; Pham, B.T. Torrential rainfall-triggered shallow landslide characteristics and susceptibility assessment using ensemble data-driven models in the Dongjiang Reservoir Watershed, China. Nat. Hazards 2019, 97, 579-609. [CrossRef]

37. Kornejady, A.; Ownegh, M.; Bahremand, A. Landslide susceptibility assessment using maximum entropy model with two different data sampling methods. CATENA 2017, 152, 144-162. [CrossRef]

38. Huang, F.; Cao, Z.; Jiang, S.-H.; Zhou, C.; Huang, J.; Guo, Z. Landslide susceptibility prediction based on a semi-supervised multiple-layer perceptron model. Landslides 2020, 17, 2919-2930. [CrossRef]

39. Hosmer, D.W.; Lemeshow, S. Applied Logistic Regression, 2nd ed.; John Wiley and Sons, Inc.: New York, NY, USA, 2000; 375p, Available online: http:/ / www.nesug.org/proceedings/nesug06/an/da26.pdf (accessed on 21 September 2021).

40. Umar, Z.; Pradhan, B.; Ahmad, A.; Jebur, M.N.; Tehrany, M.S. Earthquake induced landslide susceptibility mapping using an integrated ensemble frequency ratio and logistic regression models in West Sumatera Province, Indonesia. CATENA 2014, 118, 124-135. [CrossRef]

41. Pradhan, B.; Jebur, M.N. Spatial prediction of landslide-prone areas through K-nearest neighbor algorithm and logistic regression model using high resolution airborne laser scanning data. In Laser Scanning Applications in Landslide Assessment; Springer: Cham, Switzerland, 2017; pp. 151-165.

42. Bezdek, J.C. Pattern Recognition with Fuzzy Objective Function Algorithms; IEEE Electrical Insulation Magazine; Plenum Press: New York, NY, USA, 1981.

43. Sun, X.-L.; Zhao, Y.-G.; Wang, H.-L.; Yang, L.; Qin, C.-Z.; Zhu, A.-X.; Zhang, G.-L.; Pei, T.; Li, B.-L. Sensitivity of digital soil maps based on FCM to the fuzzy exponent and the number of clusters. Geoderma 2011, 171-172, 24-34. [CrossRef]

44. Wang, J.; Chen, J.; Yang, J. Application of distance discriminant analysis method in classification of surrounding rock mass in highway tunnel. J. Jilin Univ. Earth Sci. Ed. 2008, 38, 999-1004. [CrossRef]

45. Varnes, D.J. Landslide Hazard Zonation: A Review of Principles and Practice; Commission on Landslides of the IAEG, UNESCO Natural Hazards No. 3; UNESCO: Paris, France, 1984; p. 61.

46. Chung, C.-J.F.; Fabbri, A.G. Validation of Spatial Prediction Models for Landslide Hazard Mapping. Nat. Hazards 2003, 30, 451-472. [CrossRef]

47. Guzzetti, F.; Reichenbach, P.; Ardizzone, F.; Cardinali, M.; Galli, M. Estimating the quality of landslide susceptibility models. Geomorphology 2006, 81, 166-184. [CrossRef]

48. James, G.; Witten, D.; Hastie, T.; Tibshirani, R. An Introduction to Statistical Learning; Springer: New York, NY, USA, 2013 ; p. 441.

49. Chen, J.; Pi, D. A Cluster Validity Index for Fuzzy Clustering Based on Non-distance. In Proceedings of the 2013 International Conference on Computational and Information Sciences, Shiyang, China, 21-23 June 2013; pp. 880-883.

50. Ozdemir, A.; Altural, T. A comparative study of frequency ratio, weights of evidence and logistic regression methods for landslide susceptibility mapping: Sultan Mountains, SW Turkey. J. Asian Earth Sci. 2013, 64, 180-197. [CrossRef]

51. Dou, J.; Yunus, A.P.; Merghadi, A.; Shirzadi, A.; Nguyen, H.; Hussain, Y.; Avtar, R.; Chen, Y.; Pham, B.T.; Yamagishi, H. Different sampling strategies for predicting landslide susceptibilities are deemed less consequential with deep learning. Sci. Total Environ. 2020, 720, 137320. [CrossRef] [PubMed]

52. Bui, D.T.; Shirzadi, A.; Shahabi, H.; Geertsema, M.; Omidvar, E.; Clague, J.J.; Pham, B.T.; Dou, J.; Asl, D.T.; Bin Ahmad, B.; et al. New Ensemble Models for Shallow Landslide Susceptibility Modeling in a Semi-Arid Watershed. Forests 2019, 10, 743. [CrossRef]

53. Lian, C.; Zeng, Z.; Yao, W.; Tang, H. Extreme learning machine for the displacement prediction of landslide under rainfall and reservoir level. Stoch. Environ. Res. Risk Assess. 2014, 28, 1957-1972. [CrossRef]

54. Zhang, Y.-X.; Lan, H.-X.; Li, L.-P.; Wu, Y.-M.; Chen, J.-H.; Tian, N.-M. Optimizing the frequency ratio method for landslide susceptibility assessment: A case study of the Caiyuan Basin in the southeast mountainous area of China. J. Mt. Sci. 2020, 17, 340-357. [CrossRef] 
55. Park, S.; Hamm, S.-Y.; Kim, J. Performance Evaluation of the GIS-Based Data-Mining Techniques Decision Tree, Random Forest, and Rotation Forest for Landslide Susceptibility Modeling. Sustainability 2019, 11, 5659. [CrossRef]

56. Wang, Y.; Fang, Z.; Hong, H. Comparison of convolutional neural networks for landslide susceptibility mapping in Yanshan County, China. Sci. Total Environ. 2019, 666, 975-993. [CrossRef]

57. Wang, L.-J.; Sawada, K.; Moriguchi, S. Landslide susceptibility analysis with logistic regression model based on FCM sampling strategy. Comput. Geosci. 2013, 57, 81-92. [CrossRef]

58. Breiman, L. Random forests. Mach. Learn. 2001, 45, 5-32. [CrossRef]

59. Chen, T.; Zhu, L.; Niu, R.-Q.; Trinder, C.J.; Peng, L.; Lei, T. Mapping landslide susceptibility at the Three Gorges Reservoir, China, using gradient boosting decision tree, random forest and information value models. J. Mt. Sci. 2020, 17, 670-685. [CrossRef]

60. Arabameri, A.; Pradhan, B.; Rezaei, K.; Sohrabi, M.; Kalantari, Z. GIS-based landslide susceptibility mapping using numerical risk factor bivariate model and its ensemble with linear multivariate regression and boosted regression tree algorithms. J. Mt. Sci. 2019, 16, 595-618. [CrossRef]

61. Song, Y.; Niu, R.; Xu, S.; Ye, R.; Peng, L.; Guo, T.; Li, S.; Chen, T. Landslide Susceptibility Mapping Based on Weighted Gradient Boosting Decision Tree in Wanzhou Section of the Three Gorges Reservoir Area (China). ISPRS Int. J. Geo-Inf. 2019, 8, 4. [CrossRef]

62. Tehrany, M.S.; Kumar, L.; Jebur, M.N.; Shabani, F. Evaluating the application of the statistical index method in flood susceptibility mapping and its comparison with frequency ratio and logistic regression methods. Geomat. Nat. Hazards Risk 2018, 10, 79-101. [CrossRef]

63. Chang, Z.; Du, Z.; Zhang, F.; Huang, F.; Chen, J.; Li, W.; Guo, Z. Landslide Susceptibility Prediction Based on Remote Sensing Images and GIS: Comparisons of Supervised and Unsupervised Machine Learning Models. Remote Sens. 2020, 12, 502. [CrossRef]

64. Zhu, Q.; Chen, L.; Hu, H.; Pirasteh, S.; Li, H.; Xie, X. Unsupervised Feature Learning to Improve Transferability of Landslide Susceptibility Representations. IEEE J. Sel. Top. Appl. Earth Obs. Remote Sens. 2020, 13, 3917-3930. [CrossRef] 